\title{
LA GRAN TRANSFORMACIÓN DE LA FAMILIA ESPAÑOLA DURANTE LA SEGUNDA MITAD DEL SIGLO XX
}

\author{
Salustiano del Campo \\ María del Mar Rodríguez-Brioso
}

\begin{abstract}
RESUMEN
La transición desde la familia extensa a la familia nuclear se produjo en España antes de los años cincuenta, fecha en la que el patrón de la conyugalidad, junto con una fecundidad limitada y decreciente, se impusieron entre nosotros. Los años sesenta fueron decisivos para la sociedad española y, dentro de ella, muchos cambios en la familia obtuvieron una gran repercusión, como la reducción del tamaño medio de la familia, por la reducción de la natalidad y la salida de los hogares de otros parientes.

A partir de los años ochenta, la evolución se acentuó y la familia nuclear dejó de ser casi universal, aproximándose a las pautas prevalecientes en Europa, aunque conservando algunas particularidades compartidas con otros países mediterráneos. Además, la nueva transformación de la familia se desvinculó de los parámetros estructurales que caracterizaron el cambio de sociedad tradicional a sociedad industrial avanzada, pasando a ser eminentemente cultural, como se refleja en características tales como el aumento de los hijos extramatrimoniales y de las parejas consensuales, las familias monoparentales y las tensiones familiares derivadas del cambio del estatus de la mujer en la sociedad.

La planificación de la familia se ha generalizado y, a pesar de haberse despenalizado el aborto en determinados casos, la opinión es contraria a hacerlo plenamente libre. Las relaciones familiares se acercan progresivamente a la igualdad entre los cónyuges y así se refleja en la toma de decisiones y en la ayuda familiar. La conflictividad en los matrimonios españoles es relativamente baja y las rupturas matrimoniales no han alcanzado los mismos niveles que en Europa. Y en cuanto a la política familiar, en el artículo se detallan las reformas legales, tanto civiles como penales, y la evolución de la protección social de la familia desde 1943 hasta el presente.
\end{abstract}


La familia española ha experimentado en la segunda mitad del siglo XX numerosos cambios que guardan relación con las transformaciones de nuestra sociedad. Primero, con el proceso de desarrollo económico y de industrialización iniciado en los años sesenta; después, con la transición a la democracia y su consolidación. Como otros países de nuestro entorno, hemos pasado en un breve periodo de tiempo desde un modelo familiar que llegó a ser casi universal, el de la familia nuclear, a la coexistencia de diversos tipos de familia, si bien esta transformación ha sido menos intensa entre nosotros que en muchos otros países europeos, según lo acreditan los datos que se aportan aquí.

Los cambios operados en el interior de la familia española han sido múltiples: demográficos —en cuanto al tamaño, la diversidad de tipos de hogar y las características en las diferentes etapas del ciclo vital, por ejemplo-; de las actitudes y comportamientos; de los derechos y estatus de los miembros de la familia; de las relaciones de pareja y entre padres e hijos; de la armonía conyugal y de la simetría de la pareja, y otros paralelos que, sumados, la hacen muy diferente de la de antaño.

La aceptación de la disolución familiar voluntaria y las nuevas pautas demográficas han motivado que, al lado de la familia tradicional, hayan surgido otros modelos de convivencia expresivos de un cambio de mentalidad y con una presencia significativa y creciente a pesar de seguir siendo minoritarias: parejas cohabitantes, familias monoparentales, hogares unipersonales, familias recompuestas y otros. En definitiva, cabe afirmar que la familia española ha sido objeto de un importante proceso adaptativo a las nuevas condiciones económicas, sociales y culturales, que aún continúa abierto.

\section{CAMBIOS DEMOGRÁFICOS}

Históricamente, el primer acontecimiento demográfico reciente que podemos calificar de trascendental fue el de los grandes desplazamientos de población que se sucedieron a lo largo de los años sesenta y duraron hasta el primer quinquenio de los setenta, tanto los orientados al interior, a las regiones más industrializadas y a las grandes ciudades, como los que se dirigieron a otros países de Europa, y, ya en la última década del siglo, la llegada de inmigrantes que nos ha convertido en país receptor.

Una de las consecuencias más importantes ha sido que España dejó de ser un país eminentemente rural para convertirse en una sociedad urbana moderna, industrial y tecnológica. En consonancia con ello, las formas familiares vinculadas con la vida rural tendieron a la extinción, en especial la familia extensa, decayendo algunos de sus rasgos más distintivos, como la preeminencia de los varones y de los primogénitos, la relegación de la mujer, la autoridad de los ancianos y la pronta transición de la infancia a la vida adulta.

a) Cambios en el tamaño de la familia. Las nuevas formas de vida obligaron a una rápida respuesta por parte de la familia, que se cerró sobre el núcleo 
formado por los padres y los hijos. A pesar de que las pautas de fecundidad tardaron en adaptarse y sólo se redujeron de una manera significativa a finales de los años setenta, el tamaño medio de la familia había venido disminuyendo desde el fin de la guerra civil ${ }^{1}$ y alcanzó la magnitud de 3,07 miembros en el año 2001, como muestra el cuadro 1 .

\section{CUADRO 1}

Tamaño medio de la familia española, 1857-2000

\begin{tabular}{|c|c|c|}
\hline & Años & Número de personas \\
\hline 1857 & $\ldots$ & 4,50 \\
\hline 1900 & 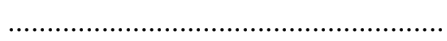 & 3,87 \\
\hline 1910 & (2) & 3,98 \\
\hline 1920 & (1) & 4,08 \\
\hline 1930 & 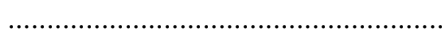 & 4,09 \\
\hline 1940 & . & 4,22 \\
\hline 1950 & , & 3,74 \\
\hline 1960 & , & 4,00 \\
\hline 1970 & (2) & 3,81 \\
\hline 1981 & - & 3,51 \\
\hline 1991 & , & 3,29 \\
\hline 1997 & 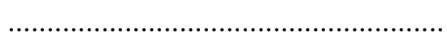 & 3,12 \\
\hline 2001 & 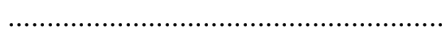 & 3,07 \\
\hline
\end{tabular}

Fuentes: Hasta 1960, FOESSA 1970. Para 1970 y 1981, Censo de Población, 1981. Para 1991, Encuesta Sociodemográfica. Dato 2000, Encuesta de Presupuestos Familiares, 2000.

Este descenso se debe en parte a la exclusión de la convivencia dentro del hogar de los muchos parientes que antes habitaban en él, como los propios hijos casados, pero sobre todo a la reducción del número de hijos, que se acentúa sensiblemente durante los años ochenta. Así, cuando analizamos el tamaño medio de las familias por regiones, comprobamos que en 1970 las que tenían familias más amplias eran Andalucía, Canarias, Cantabria, Navarra y el País Vasco. En estas tres últimas, la familia extensa podía ser un factor cultural de peso, pero en las dos primeras eran más bien las elevadas tasas de natalidad las que hacían crecer el número medio de hijos y, por tanto, el de miembros de la familia. En

${ }^{1}$ Muchos de los datos que se citan en este epígrafe proceden de las estadísticas de población, pero se toman ya elaborados de S. del Campo y Manuel Navarro, Análisis sociológico de la familia española, Ariel, Barcelona, 1985. Un examen del tamaño de la familia puede encontrarse en Lluis Flaquer y Juan Soler, Permanencia y cambio de la familia española, Estudios y Encuestas, 18, CIS, 1990. 
1991 y dentro de una tónica general de reducción del número de miembros, que descendió desde ser el 3,8 en 1970 a ser el 3,3 en 1991, únicamente Canarias mantenía un tamaño medio de 3,7, y Andalucía, Cantabria, Galicia, Murcia y Navarra también sobrepasaban levemente el promedio nacional.

Desde 1970 el número de hogares ha aumentado progresivamente, alcanzando en 2000 la cifra de 12.757.012. Esto se produce paralelamente a la tendencia de disminución del tamaño medio de la familia en todas las Comunidades Autónomas, manteniéndose las pautas de comportamiento de cada una. En la última fecha citada, las Comunidades Autónomas que están por encima de la media son Andalucía, Canarias, Galicia, Murcia y Ceuta y Melilla (3,27, 3,41, 3,34, 3,25 y 3,49, respectivamente), siendo Melilla la Comunidad con la tasa de natalidad más alta $(18,63)^{2}$. Por el contrario, las Comunidades Autónomas que están por debajo de la media son Baleares, Aragón y Castilla y León (2,74, 2,85 y 2,84 , respectivamente).

En un interesante estudio, Montserrat Solsona y Rocío Treviño ${ }^{3}$ sintetizaron los cuatro modelos regionales aún vigentes en 1981: 1) modelo complejo tradicional norte, que abarcaba Galicia, Asturias, Cantabria, País Vasco, Navarra, Huesca y norte de Cataluña, donde la familia troncal seguía teniendo un peso considerable; 2) modelo familiar complejo andaluz, ubicado en Andalucía occidental y caracterizado porque las familias de estructura compleja son más frecuentes en la zona urbana que en la rural; 3) modelo nuclear tradicional, propio de Levante, Andalucía oriental y algunas provincias como Madrid, Zaragoza, Valladolid y La Rioja; y 4) modelo nuclear castellano, presente en la mayor parte de la mitad norte peninsular, donde hay también una fuerte presencia de hogares solitarios y de población vieja.

En su trabajo sobre las estructuras familiares complejas en los años noventa, Miguel Requena llegó a la conclusión de que en el actual clima de acelerado cambio de la institución familiar «las familias de estructuras complejas se presentan, ante todo, como una suerte de reliquia institucional $»^{4}$. En consecuencia, entre 1970 y 1990 las familias múltiples descendieron desde el 5,83 al $2,67 \%$, y esta disminución de un $40 \%$ es paralela a la de la familia extensa, que también reduce su número y proporción en esos años.

b) Hogares y familias. La disminución del tamaño medio de la familia española desde 1900 implica un descenso del 15 por 1.000 aproximadamente, que es paralelo al experimentado en los demás países europeos y algo superior al 14\% del periodo que se abre en 1857 y se cierra en el año inicial del siglo

2 España en Cifras, 2002, INE.

3 Montserrat Solsona y Rocío Treviño, Estructuras familiares en España, Ministerio de Asuntos Sociales, 1990, pp. 133-134.

${ }^{4}$ Miguel Requena, «Estructuras familiares complejas: la formación de familias múltiples en España", Revista Internacional de Sociología, n.o 10, abril-mayo 1995, p. 10. También puede verse Miguel Requena, "Formas de familia en la España contemporánea», en Luis Garrido Medina y Enrique Gil Calvo (eds.), Estrategias familiares, Alianza Universidad, Madrid, 1993, pp. 249-270. 


\section{CUADRO 2}

Tamaño medio de las familias españolas por Comunidades Autónomas

\begin{tabular}{|c|c|c|c|c|c|c|c|c|}
\hline \multirow[b]{2}{*}{ CC.AA. } & \multicolumn{4}{|c|}{ Número de familias } & \multicolumn{4}{|c|}{ Tamaño medio de la familia } \\
\hline & 1970 & 1981 & 1991 & 2000 & 1970 & 1981 & 1991 & 2000 \\
\hline TOTAL ....... & 8.860 .175 & 10.665 .199 & 11.824 .851 & 12.757 .012 & 3,8 & 3,5 & 3,3 & 3,07 \\
\hline Andalucía ........... & 1.481 .112 & 1.704 .080 & 1.961 .727 & 2.205 .391 & 4,0 & 3,8 & 3,5 & 3,27 \\
\hline Aragón ............... & 318.889 & 363.768 & 396.835 & 406.682 & 3,6 & 3,3 & 3,1 & 2,85 \\
\hline Asturias ............... & 285.506 & 330.676 & 356.045 & 332.812 & 3,7 & 3,4 & 3,1 & 3,13 \\
\hline Baleares ................ & 160.357 & 204.760 & 234.074 & 270.343 & 3,5 & 3,2 & 3,1 & 2,74 \\
\hline Canarias ............. & 275.428 & 351.535 & 397.168 & 471.937 & 4,3 & 3,9 & 3,7 & 3,41 \\
\hline Cantabria .......... & 118.012 & 141.152 & 155.228 & 164.164 & 4,0 & 3,6 & 3,4 & 3,17 \\
\hline C.-La Mancha .. & 469.402 & 473.835 & 509.610 & 861.262 & 3,6 & 3,5 & 3,2 & 3,09 \\
\hline Castilla y León . & 718.066 & 761.743 & 801.328 & 553.643 & 3,7 & 3,4 & 3,1 & 2,84 \\
\hline Cataluña ............ & 1.356 .880 & 1.777 .163 & 1.947 .796 & 2.035 .138 & 3,8 & 3,3 & 3,1 & 2,95 \\
\hline C. Valenciana ... & 845.260 & 1.066 .089 & 1.212 .431 & 1.352 .988 & 3,6 & 3,4 & 3,2 & 2,97 \\
\hline Extremadura .... & 301.988 & 299.739 & 317.440 & 356.919 & 3,8 & 3,5 & 3,3 & 3,02 \\
\hline Galicia ................ & 667.459 & 755.319 & 787.936 & 843.071 & 3,9 & 3,7 & 3,5 & 3,20 \\
\hline Madrid .............. & 980.627 & 1.347 .497 & 1.543 .797 & 1.631 .310 & 3,9 & 3,5 & 3,3 & 3,07 \\
\hline Murcia ................. & 218.572 & 257.702 & 297.827 & 341.142 & 3,8 & 3,7 & 3,5 & 3,25 \\
\hline Navarra .................. & 112.260 & 139.301 & 156.435 & 180.978 & 4,1 & 3,6 & 3,4 & 2,90 \\
\hline País Vasco ......... & 454.618 & 584.333 & 632.948 & 654.873 & 4,1 & 3,6 & 3,3 & 3,08 \\
\hline La Rioja ............. & 65.070 & 75.466 & 84.679 & 81.749 & 3,6 & 3,3 & 3,1 & 3,13 \\
\hline Ceuta y Melilla & 30.669 & 31.041 & 31.547 & 39.611 & 4,3 & 3,8 & 4,0 & 3,49 \\
\hline
\end{tabular}

Fuentes: INE, Censo de Viviendas, 1981, y Censo de Población y Viviendas, 1991, Muestra, Avance. Dato 2000, Encuesta de Presupuestos Familiares, $3{ }^{\text {er }}$ trimestre 2000. 
Xx, habiendo sido el descenso, entre 1857 y 1991, del 27\%. Asunto distinto es el registro del número de personas que comparten en una fecha determinada un mismo hogar, puesto que aunque las definiciones de hogar y familia coinciden en que en uno y en otros se dan la convivencia con otras personas y una economía común, el concepto de hogar no requiere que haya parentesco entre quienes lo componen y puede, por tanto, ser uni o pluripersonal, mientras que la familia implica siempre una pluralidad de personas.

La evolución del número de miembros del hogar en las últimas tres décadas se distribuye según muestra el cuadro 3, en el cual podemos ver que han aumentado los hogares de tres o menos miembros, se mantienen estables los de cuatro y disminuyen los de cinco y más. Actualmente, el 62,3\% de los hogares españoles tienen tres o menos miembros y sólo el 13,5\% lo forman cinco o más miembros. El cambio más drástico por su cuantía se da en los hogares de una sola persona, que se duplican, pasando del 7,5 al 14,4\% de los hogares entre 1970 y 1999.

\section{CUADRO 3}

Número de miembros del hogar, 1970-1999

\begin{tabular}{|c|c|c|c|c|c|c|c|}
\hline & Uno & Dos & Tres & Cuatro & Cinco & $\begin{array}{c}\text { Seis } \\
\text { y más }\end{array}$ & Total \\
\hline 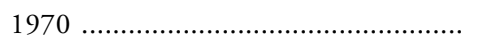 & 7,5 & 18,0 & 19,2 & 21,8 & $35,5^{*}$ & - & 100 \\
\hline 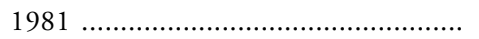 & 10,3 & 21,5 & 19,8 & 22,4 & 13,8 & 12,6 & 100 \\
\hline 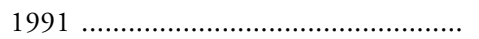 & 13,4 & 22,2 & 20,5 & 23,7 & 12,1 & 8,1 & 100 \\
\hline 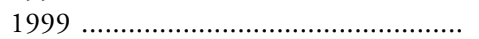 & 14,4 & 25,9 & 22,0 & 24,3 & 9,0 & 4,5 & 100 \\
\hline
\end{tabular}

* Incluye cinco o más personas.

FueNTES: A. Valero, «El sistema familiar español: Recorrido a través del último cuarto de siglo», en Revista Española de Investigaciones Sociológicas, n. ${ }^{\circ}$ 70, CIS, 1995. INE, Censo de Población, 1981; Encuesta Sociodemográfica, 1991. Dato 1999, Encuesta de Fecundidad, 1999.

En los 11.836.320 hogares investigados en 1991 en la Encuesta Sociodemográfica del Instituto Nacional de Estadística, el 13,4\% eran unipersonales y el resto pluripersonales, si bien unos y otros son diversos en su composición interna, como puede apreciarse en el cuadro sinóptico de los hogares españoles que se incluye en la página siguiente. Aunque son varias las cosas dignas de notarse en él, me limitaré a mencionar solamente un par:

1. Nada menos que el $86,5 \%$ de todos los hogares españoles son familiares, sin duda la proporción más elevada de cualquier país europeo.

2. Casi el $93 \%$ de los hogares unipersonales son de viudos o de solteros. 


\section{CUADRO 4}

Cuadro sinóptico de los hogares españoles (miles), 1991

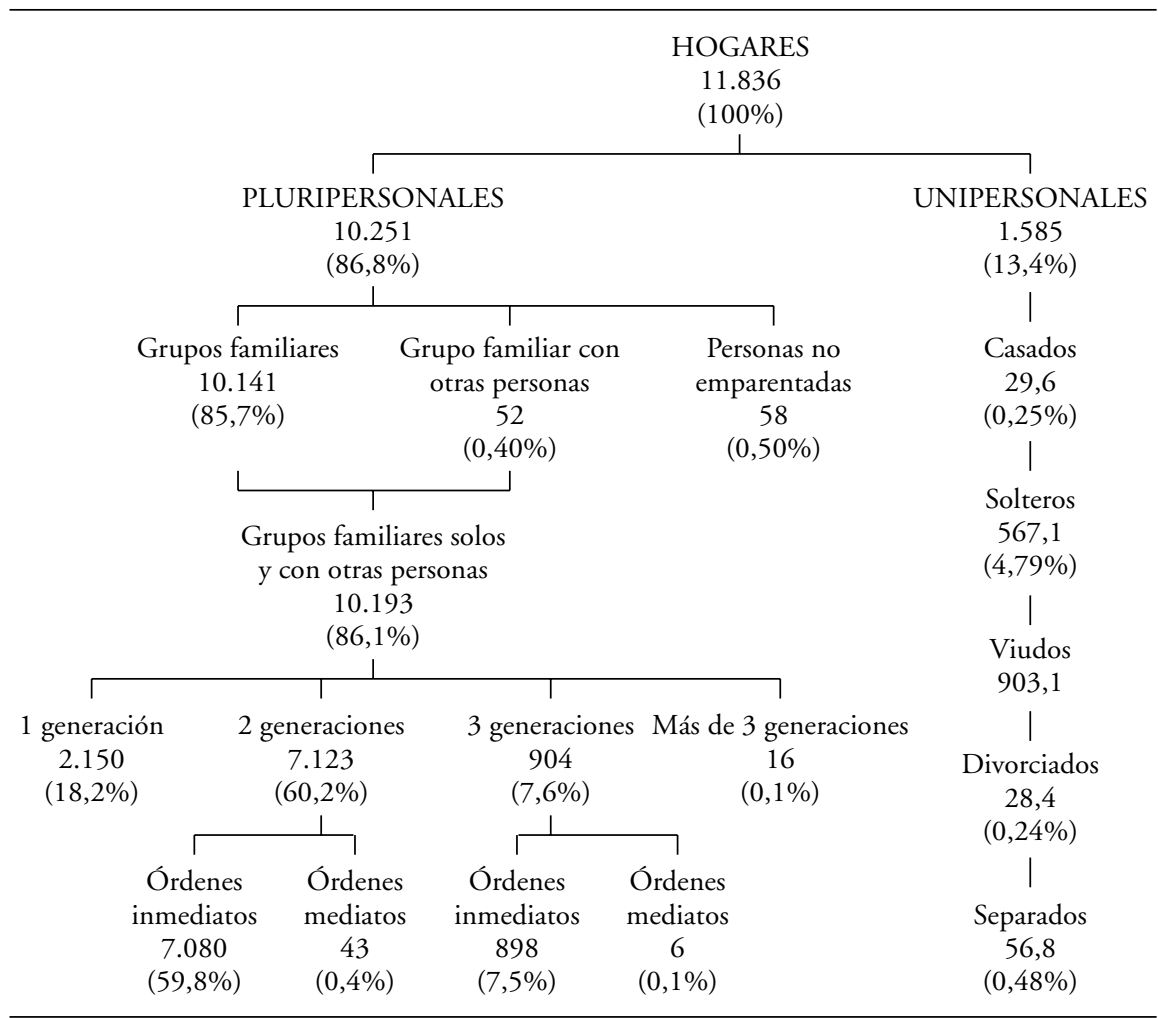

FUENTE: INE, Encuesta Sociodemográfica, 1991, tomo II, vol. I, cuadros V.1.22, V.1.23 y V.4.32. Elaboración propia.

El número total de hogares aumentó respecto a 1970 en un $25 \%$. Sin embargo, este aumento no se comportó uniformemente en todos los tipos de hogares. Los hogares unipersonales aumentaron un 140\% debido principalmente a los de personas viudas. Una evolución contraria, aunque no de la misma cuantía, la han sufrido los hogares de dos o más núcleos, que han visto reducida su presencia en un $29 \%$, cediendo el mayor protagonismo a la forma de convivencia hegemónica de los hogares en nuestro país, la de un solo núcleo, que aumenta en un $37,1 \%$.

5 Ángeles Valero, «El sistema familiar español: Recorrido a través del último cuarto de siglo», en REIS, n. ${ }^{\circ}$ 70, CIS, 1995; INE, Censo de Población, 1981, y Encuesta Sociodemográfica, 1991. 
Esta hegemonía de los hogares de un solo núcleo no supone una única forma de convivencia de las familias españolas. A partir de los datos ofrecidos por la Oficina Estadística Europea (Eurostat), para el año 2000, podemos ofrecer la clasificación que se muestra en el cuadro 5 . Según se desprende de sus datos, el $47 \%$ se clasifican como familias nucleares, integradas por ambos progenitores e hijos; el $19 \%$ de hogares son parejas sin hijos, y el $8 \%$ son familias monoparentales de un solo progenitor, que es, en el $87 \%$ de los casos, mujer ${ }^{6}$.

\section{CUADRO 5}

Composición de los hogares, 2000

\begin{tabular}{|c|c|}
\hline Unipersonales & 14 \\
\hline 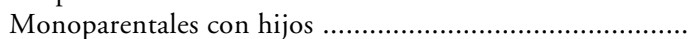 & 8 \\
\hline Parejas sin hijos & 19 \\
\hline 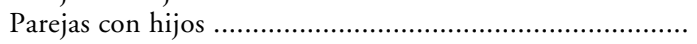 & 47 \\
\hline 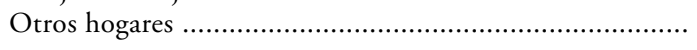 & 12 \\
\hline TOTAL .. & 100 \\
\hline
\end{tabular}

Fuente: Clasificación 2. Panel de Hogares de la Unión Europea, 2000, Eurostat.

La singularidad de la composición de los hogares se entiende mucho mejor si se la compara, aunque sólo sea someramente, con la del principal país de la Unión Europea, en el que los hogares unipersonales de solteros o viudos eran en 1986 solamente el 82,4\%, mientras que los de divorciados y separados, que en España alcanzaban el 5,4\% (ver cuadro 6), ascendían en la antigua República Federal Alemana al 18\%. El tiempo, sin embargo, puede ver reducida en un futuro no muy lejano esta gran diferencia, ya que las tasas de divorcio españolas, que ahora son aún bajas, pueden subir considerablemente en los próximos años.

La diferencia entre los hogares pluripersonales de la vieja Alemania Occidental y de España por las mismas fechas era mayor todavía, empezando porque la proporción de familias compuestas de casados sin hijos era superior en aquel país $(22,6 \%$ frente a $17,0 \%)$ y, por el contrario, las formadas por casados con hijos son muchas más entre nosotros: $53,1 \%$ frente a $31,9 \%{ }^{7}$.

Por otro lado, tanto las familias monoparentales, que en España constituían el 7,8\% del total (unas 973.000 sobre 10.700 .000 grupos familiares), como aquellas en las que convivían tres generaciones o más, que eran el 7,2\%

${ }^{6}$ Diego Ruiz Becerril, Después del divorcio. Los efectos de la ruptura matrimonial, Monografía 169, CIS, 1999.

7 Charlotte Hönh y Kurt Lüscher, "The changing family in the Federal Republic of Germany", Journal of Family Issues, vol. 9, n. ${ }^{\circ}$ 3, septiembre 1988, pp. 317-335. 


\section{CUADRO 6}

Comparación entre los hogares privados en Alemania y España por tipos de hogar

\begin{tabular}{|c|c|c|c|c|}
\hline \multirow[b]{2}{*}{ Tipos de hogar } & \multicolumn{2}{|c|}{ España (1991) } & \multicolumn{2}{|c|}{ Alemania (1985) } \\
\hline & Total (000) & Porcentaje & Total (000) & Porcentaje \\
\hline Hogares privados ....................... & 11.836 & 100 & 26.367 & 100 \\
\hline Unipersonales ........................... & 1.585 & 13,4 & 8.863 & 33,6 \\
\hline De solteros ............................ & 567,1 & 4,8 & 3.480 & 13,2 \\
\hline 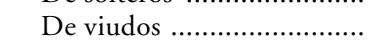 & 903,1 & 7,6 & 3.823 & 14,5 \\
\hline De divorciados . ..................... & 28,4 & 0,2 & 1.055 & 4,0 \\
\hline De separados ........................ & 56,8 & 0,5 & 501 & 1,9 \\
\hline De casados ............................ & 29,6 & 0,3 & - & - \\
\hline Pluripersonales ........................ & 10.251 & 86,8 & 17.504 & 66,4 \\
\hline Grupos familiares ................. & 10.141 & 85,7 & 16.555 & 62,8 \\
\hline 1 generación ..................... & 2.150 & 18,2 & 5.944 & 22,6 \\
\hline 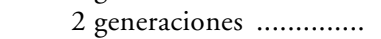 & 7.123 & 60,2 & 10.149 & 38,5 \\
\hline 3 generaciones o más .... & 920 & 7,8 & 452 & 1,7 \\
\hline $\begin{array}{c}\text { Grupos familiares con otras } \\
\text { personas }\end{array}$ & 52 & 0,4 & 180 & 0,7 \\
\hline Grupos no familiares .......... & 58 & 0,5 & 770 & 2,9 \\
\hline
\end{tabular}

FUENTE: C. Höhn y K. Lüscher, op. cit.

o unas 904.000, excedían a las proporciones respectivas que esos mismos tipos de familia abarcaban en la ex República Federal Alemana: 6,6\% las familias monoparentales y un reducido $1,7 \%$ las de tres generaciones o más. Claro que con esto no se ha dicho todo sobre estas dos clases de familias, porque su composición interna ofrecía y ofrece también algunas variantes.

Una visión más adecuada de los tipos de hogar y de familia existentes en España en la actualidad y de su evolución a lo largo de la última década puede obtenerse utilizando otros datos cuya presentación detallada no es de este lugar. Con ellos se comprueban el incremento experimentado entre nosotros en los últimos diez años por los hogares con núcleo conyugal, así como la importante reducción de las familias extensas a la que ya se ha aludido. Esto segundo, en línea con lo que sucede en nuestro Continente, y lo primero, en sentido divergente de la tendencia europea dominante.

Pero hay en el tema de los hogares una cuestión que merece también comentario. Concierne específicamente a los hogares unipersonales, a los que Lamo de Espinosa dedicó en 1983 un sugerente artículo en El Pais ${ }^{8}$, que

${ }^{8}$ Emilio Lamo de Espinosa, «¿Tiene futuro la familia?», El Pais, 13 de febrero de 1983. 
comenté en el prólogo de un libro mío sobre la familia9. Sus dos afirmaciones principales eran la de que «la familia continúa perdiendo terreno no ya funcionalmente sino numéricamente» y la de que "para muchas sociedades avanzadas el futuro de la familia es progresivamente independiente del futuro de la sociedad, pues un sector creciente de ésta, gracias a los avances de la salud colectiva, se ha visto liberado de las necesidades reproductivas y, por tanto, de la familia».

Como hemos podido ver en el cuadro 2, el número de familias en España aumentó entre 1970 y 2000 en 3.897.676, que equivale a un 44\%, a pesar de lo cual nuestro país sigue teniendo, juntamente con Portugal e Irlanda, el mayor número de miembros por familia de la Unión Europea. A su vez, los hogares unipersonales españoles, que, como se ve en el cuadro 7 , aparecen en 1970 cifrados en el 14\%, parecen haber dado un gran salto hasta el $20,7 \%$ en el aún inédito Censo de Población de 2001. De ser cierto, este gran cambio se ha producido sin indicios previos. Precisamente la publicación de Eurostat sobre la situación social en la Unión Europea, aparecida en 2002, hace notar que «en 2000 se estimaba que el $12 \%$ de la población de la Unión Europea vivía en hogares unipersonales, frente al $8 \%$ de 1981. La proporción de personas que así vivían es superior en los países nórdicos (17-20\%) y mínima (5\%) en España y Portugal» ${ }^{10}$.

Tan gran discrepancia en datos muy notorios nos hace recordar cómo el Censo de 1991 infraenumeró exageradamente la población y hubo de ser corregido tras realizarse la Encuesta Sociodemográfica de 1961. Además, como muestra el mismo cuadro, el porcentaje de personas solitarias disminuyó entre 1981 y 1998 en casi todos los países europeos, siendo diferentes para cada uno los puntos de partida y los ritmos de avance.

Lo más significativo, sin embargo, es que se ha comprobado que «no se pueden amalgamar monorresidencialidad y aislamiento: las personas que viven solas tienen más lazos sociales en el exterior de los domicilios que los hogares pluripersonales. Más que una modalidad de aislamiento social, la monorresidencialidad representa de hecho otra forma de inscripción doméstica y relacional $»^{11}$.

Algunas ideas tomadas de un reciente informe social y cultural holandés sirven para aclarar por qué «aunque continúa la individualización, el creciente número de hogares unipersonales no debe interpretarse como señal de una importancia decreciente de la familia en la vida de estos individuos». Dice así el informe:

9 Salustiano del Campo y Manuel Navarro, Análisis sociológico de la familia española, Ariel, Barcelona, 1985, pp. 5-13.

${ }^{10}$ Jean-Claude Kauffman, «Les menages d'une personne en Europe», Population, 4-5, 1994, pp. $935-958$.

${ }_{11}$ J. C. Kauffman, op. cit., p. 954. 


\section{CUADRO 7}

Personas solitarias en la Unión Europea

\begin{tabular}{|c|c|c|c|}
\hline Paises & c. 1950 & 1988 & 1998 \\
\hline Bélgica ................. & 16 & 23 & 18 \\
\hline 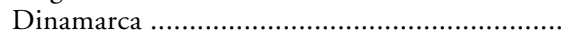 & 14 & 34 & 28 \\
\hline República Federal Alemana .................................. & 12 a 19 & 34 & 17 \\
\hline 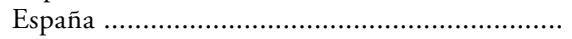 & - & 10 & 9 \\
\hline 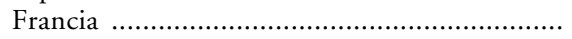 & 19 & 26 & 19 \\
\hline 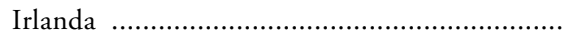 & 10 & 17 (c. 1980) & 14 \\
\hline Italia & 10 & 18 & 11 \\
\hline 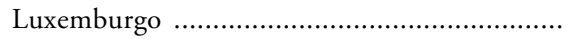 & 9 & 21 & 22 \\
\hline 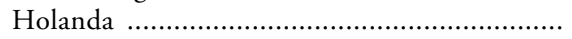 & 9 & 23 & 22 \\
\hline 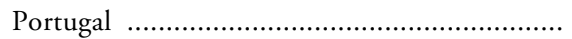 & 8 & 13 & 9 \\
\hline 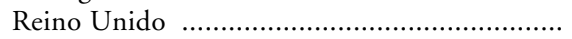 & 11 & 22 & 17 \\
\hline 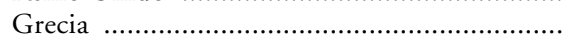 & 9 & $15($ c. 1980$)$ & 9 \\
\hline
\end{tabular}

Fuentes: Kauffman, op. cit. Dato 1998, Eurostat, elaboración propia, Panel de Hogares de la Unión Europea, 1998.

«La familia nuclear tradicional es cada vez menos común, pero esto se debe en gran medida a que ha cambiado la tradicional división de roles entre hombres y mujeres... La población sigue muy orientada hacia la formación de la familia y, en un sentido emocional, posiblemente invierte más en ello que nunca antes y no ya en la relación de pareja, sino en la paternidad. Las alternativas a la familia (vida solitaria, "relaciones viviendo separados", familias monoparentales y comunas) son consideradas satisfactorias únicamente por una proporción (limitada) de la población. Análogamente, la familia sin hijos es juzgada como ideal por muy pocos. Tales alternativas son, sin embargo, cada día más frecuentes y también más aceptadas como soluciones temporales o como situaciones impuestas por el destino. La diversidad se exagera a menudo; si se prescinde de lo que gradualmente se ha convertido en una distinción puramente nominal entre matrimonio y cohabitación, el panorama del grupo social primario sigue estando dominado por la familia nuclear.

El aumento del número de solitarios no ofrece ninguna duda, pero no es un rechazo de la familia; claramente el proceso de envejecimiento impone ya este estatus a un gran número de individuos. Otras personas que viven solas lo consideran como un estadio a veces agradable, pero sin embargo transitorio, previo a una cohabitación o situado entre una anterior y otra posterior. Uno se puede referir a este fenómeno como "desvinculación friccional". La menguante proporción de familias nucleares dentro del número total de grupos sociales primarios no debe 
interpretarse como una rebaja de la importancia de la familia en la vida de los individuos» ${ }^{12}$.

Tan larga cita sirve, por descontado, para calmar las persistentes inquietudes de Lamo de Espinosa, que reincidió en su vieja tesis de la desfamiliarización de la sociedad, aunque pidiendo solemnemente que alguien se ocupe en España de la familia. «Si nos descuidamos — concluye-, empezaremos a añorarla cuando ya no exista» ${ }^{13}$.

c) El ciclo vital de la familia. El descenso de la fecundidad, aunque generalizado, presenta variaciones regionales. Para el conjunto, empezó a notarse a partir del segundo quinquenio de los años sesenta, aunque suavemente, y se aceleró luego de forma drástica a partir de 1978. Como, por el contrario, en el periodo de 1956 a 1965 habíamos asistido a un pequeño baby boom, el efecto sobre el número de hijos en las familias españolas sólo comenzó a notarse con intensidad entre las que se constituyeron en los años setenta ${ }^{14}$.

Pero la evolución reciente de la natalidad española no debe de hacernos olvidar que su reducción es un fenómeno constante a lo largo del siglo XX, de tal modo que las familias de los años sesenta eran sensiblemente menos numerosas, en cuanto a parientes e hijos, que las de la generación anterior. La tasa bruta de natalidad, que en la década de 1901-1910 oscilaba en torno a 34,5, era en 1961-1965 de 21,3 y a partir de esa fecha se produce una gran caída, siendo de 18,7 en 1975 y alcanzando un mínimo de 10,03 en 2000.

\section{CUADRO 8}

Tasa de natalidad, 1950-2001

\begin{tabular}{lllllllllll}
\hline 1950 & 1955 & 1960 & 1965 & 1970 & 1975 & 1980 & 1985 & 1990 & 1995 & 2000 \\
\hline 20,18 & 20,51 & 21,73 & 21,13 & 19,50 & 18,76 & 15,22 & 11,88 & 10,33 & 9,27 & 10,03 \\
\hline
\end{tabular}

FUENTES: Los datos referidos entre 1955-1970 están citados en Agüero y Olano Rey, «La evolución reciente de la fecundidad en España», en REOP, vol. I, 1988. Los demás datos, en Indicadores Demográficos Básicos, 1975-2000, INE.

En los últimos cinco años, de 1995 a 2000, la tasa ha aumentado en casi un punto, debido en parte a la aportación que han supuesto los nacimientos

12 Social and Cultural Planning Office, Social and Cultural Report 1994, Rijswijk, febrero 1995, pp. 37-38.

13 Emilio Lamo de Espinosa, «Familias, hogares y personas», El País, 5 enero 1995. Véase también, del mismo autor, «¿Nuevas formas de familia?», Claves, n.o 50, marzo 1995, pp. 50-54.

${ }_{14}$ Cfr. Margarita Delgado y J. S. Fernández Cordón, La fecundidad en España desde 1975, Instituto de Demografía, CSIC, 1989. 
de madres extranjeras inmigrantes, que han pasado de ser el 3,26\% en 1996 a ser el 8,19\% del total de los nacimientos producidos en España en $2000^{15}$. En este sentido, hay que recordar que el número medio de hijos por española ha descendido de manera brusca, pasando de ser 3,08 en 1950 a ser 1,23 en 2001, muy lejos después de 1980 del nivel de reemplazo generacional.

\section{CUADRO 9}

Número medio de hijos por mujer

\begin{tabular}{|c|c|c|}
\hline & Años & Número de hijos \\
\hline 1950 & & 3,08 \\
\hline 1960 & .. & 3,14 \\
\hline 1965 & & 2,95 \\
\hline 1970 & 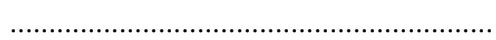 & 2,86 \\
\hline 1975 & 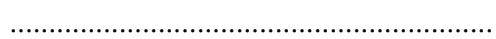 & 2,80 \\
\hline 1980 & (1) & 2,21 \\
\hline 1985 & , & 1,64 \\
\hline 1990 & 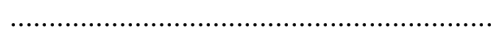 & 1,36 \\
\hline 1995 & . & 1,17 \\
\hline 2000 & . & 1,23 \\
\hline
\end{tabular}

FueNTES: Los datos entre 1955-1970 están tomados de Agüero y Olano Rey, «La evolución reciente de la fecundidad en España", en REOP, vol. I, 1988; Indicadores Demográficos Básicos, 1975-2000, INE.

La reducción de la tasa de natalidad ha tenido serias repercusiones en la familia española: primero, sobre la reducción del número de hijos y, por tanto, sobre su tamaño; y segundo, sobre su ciclo de vida, que se ha visto alterado por este y otros factores. Una de las principales modificaciones ha sido la edad media a la maternidad, que se sitúa actualmente en los 30 años. En el cuadro 10 se presentan algunos indicadores para 1900, 1970-1975, 1981-1985 y 2000.

El tiempo dedicado a la fecundidad matrimonial se ha reducido en un $54,6 \%$, desde 12,7 años en 1900 a 7,5 en 1970-1975, y a 4 años a finales de la década de los noventa. También la etapa de permanencia de los hijos en el hogar se ha acortado: a principios de siglo, el hijo menor contraía matrimonio cuando la madre tenía cerca de los 65 años y el padre más de 66, mientras que en la actualidad esas edades son de 52 años y de menos de 55, respectivamente. De modo paralelo nos encontramos con un adelanto de la etapa del «nido vacío", es decir, de aquella en la que los esposos vuelven a estar solos, después de la emancipación de los hijos, a la cual antes no llegaban demasiados matri-

15 España en Cifras, 2002, INE. 


\section{CUADRO 10}

\section{Indicadores del ciclo vital de la familia española en el siglo XX*}

\begin{tabular}{|c|c|c|c|c|}
\hline Indicadores & 2000 & $\begin{array}{c}1981- \\
1985\end{array}$ & $\begin{array}{c}1970- \\
1975\end{array}$ & 1900 \\
\hline Diferencia de edad marido-mujer al casarse .. & 2,06 & 2,7 & 1,9 & 1,9 \\
\hline Edad media de la mujer al casarse ................ & 28,1 & 22,6 & 23,7 & 24,6 \\
\hline 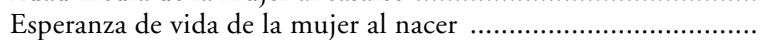 & 82,1 & 78,6 & 75,1 & 35,7 \\
\hline 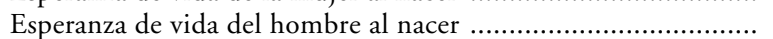 & 75,2 & 72,5 & 69,6 & 33,8 \\
\hline 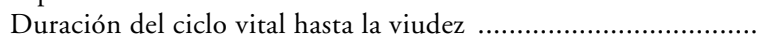 & 48,4 & 49,5 & 45,1 & 27,8 \\
\hline $\begin{array}{l}\text { Porcentaje de la duración de la vida marital sobre la vida media } \\
\text { de la mujer }\end{array}$ & $65,7^{*}$ & 63,0 & 60,0 & 77,9 \\
\hline $\begin{array}{l}\text { Porcentaje de la duración de la vida marital sobre la vida media } \\
\text { del hombre }\end{array}$ & $59.8^{*}$ & 68,3 & 64.8 & 82.2 \\
\hline 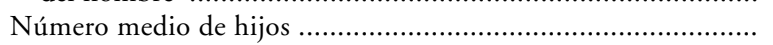 & 1,2 & 1,7 & 2,5 & 4,7 \\
\hline 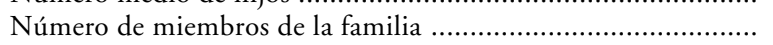 & 3,07 & 3,51 & 3,84 & 3,87 \\
\hline Etapa de nido sin usar (hasta el primer matrimonio) ................... & 2,6 & 1,2 & 1,4 & 1,9 \\
\hline 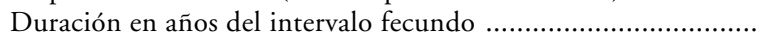 & 4,0 & 5,8 & 7,5 & 12,7 \\
\hline 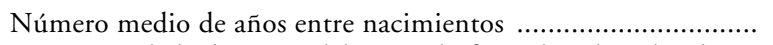 & 3,1 & 3,4 & 3,0 & 2,7 \\
\hline $\begin{array}{l}\text { Porcentaje de la duración del intervalo fecundo sobre el ciclo vi- } \\
\text { tal hasta la viudez }\end{array}$ & 12,1 & 11,7 & 16,6 & 45,7 \\
\hline Nido vacío & 18,1 & 20,0 & 11,7 & - \\
\hline $\begin{array}{c}\text { Porcentaje de la duración del nido vacío sobre el ciclo vital hasta } \\
\text { la viudez }\end{array}$ & 37,9 & 40,4 & 25,9 & - \\
\hline 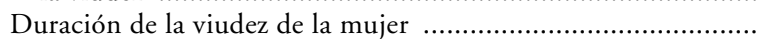 & 7,51 & 12,5 & 9,0 & 9,4 \\
\hline Duración de la viudez del hombre & 6,9 & 8,8 & 2,2 & 1,6 \\
\hline $\begin{array}{l}\text { Duración total del ciclo vital familiar masculino (incluida la viu- } \\
\text { dez) }\end{array}$ & 42,0 & 58,3 & 47,3 & 34,3 \\
\hline $\begin{array}{l}\text { Duración total del ciclo vital familiar femenino (incluida la viu- } \\
\text { dez) }\end{array}$ & 64,0 & 62,0 & 54,1 & 37,2 \\
\hline 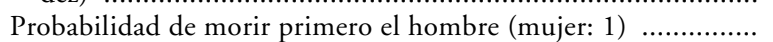 & 1,09 & 2,9 & 2,7 & 1,6 \\
\hline
\end{tabular}

* Suponiendo que no haya interrupción del matrimonio.

FuENTES: Elaboración de Del Campo para el periodo referido 1900-1985. Los datos para el año 2000, Movimiento Natural de la Población, 2000; Indicadores Demográficos Básicos, 2000; Anuario Estadistico, 2000, INE; Encuesta de Fecundidad, 1999.

monios y que ahora se ha ampliado a muchos y se prolonga, salvo por la tendencia reciente a que los hijos sin casar vivan con los padres. Según los datos más recientes del Instituto Nacional de Estadística, la edad actual de emancipación de los hombres es la de 28,5 y la de las mujeres de 27,7 años.

Como se ha dicho, el actual menor número de hijos se tiene en un periodo más breve y más concentrado en las edades inmediatas al casamiento, como consecuencia de un acortamiento de la duración de la etapa que va desde el inicio del matrimonio hasta el nacimiento del primer hijo, que se conoce con el nombre de «nido sin usar», y que de abarcar 1,9 años a principios de siglo 
pasó a comprender 1,2 en los años 1980-1985 y 2,6 años a finales de siglo. Como, por otra parte, la boda se celebra ahora a una edad algo más tardía, el resultado es que las primeras fases del ciclo de vida de la familia, a saber, la del «nido sin usar» y las que preceden a la del «nido vacío», es decir, las de crianza y educación de los hijos, duran menos que en otras épocas. Sin embargo, la etapa del nido vacío no se alarga respecto a la década de los ochenta, ya que si, por una parte, la esperanza de vida aumenta y extiende el periodo de vida marital, por otra, se ve contrarrestado por la más tardía emancipación de los hijos.

A lo anterior hay que sumar el efecto de otros dos cambios demográficos importantes, como son el descenso de la mortalidad y el aumento de la esperanza de vida. Ambos son complementarios y han acarreado diversas consecuencias para la familia: por un lado, al prolongarse la vida se ha alargado la duración del ciclo familiar, de manera que la relación de pareja entre los cónyuges dura mucho más años que antes y la viudez se produce a edades muy avanzadas en general y cuando los hijos ya han abandonado el hogar. En contrapartida, surge una nueva cuestión que afecta directamente a las relaciones familiares, que es la de la tercera edad, que desborda por sus implicaciones el marco estricto de la familia y se convierte en un problema de enorme magnitud para la sociedad.

\section{NOVIAZGO Y MATRIMONIO}

En España, donde, como en otros países, se ha dado una considerable baja de la nupcialidad — desde una tasa de 7,50 en 1950 a otra de 5,12 en el $2001^{16}$ - ésta parece denotar un distanciamiento del matrimonio como opción personal, a la vez que fomenta la aparición de formas alternativas de la familia. La reducción reciente de la edad media al casarse, que pasó de los 25,78 años para las mujeres y los 27,15 para los hombres en 1971 a los 28,12 y 30,18 , respectivamente, en 2000 , influye también de modo directo en el inicio del ciclo vital de la familia.

La etapa previa a la constitución de la familia y la formal de celebración del matrimonio son, posiblemente, los aspectos cualitativos en los que más ha cambiado la familia española. Ambos se relacionan con el nuevo papel de la juventud en la sociedad y con la manera de pensar de este grupo, más voluble e inconformista que la de otra edad. Pocas instituciones han estado sujetas a tantas, tan variadas y, a veces, tan complejas pautas culturales no escritas como el noviazgo, por más que su aparición sea relativamente reciente en la historia $^{17}$.

${ }_{16}$ Anuarios Estadisticos, 1952, 1956, 1963, 1967, 1973; Indicadores Demográficos Básicos, 1975-2000; Indicadores Sociales, 2001, INE.

${ }_{17}$ Véanse Julio Iglesias de Ussel, Sociología del noviazgo en España, Caja General de Ahorros y Monte de Piedad de Granada, Granada, 1987, y A. Ferrándiz y V. Verdú, Noviazgo y matrimonio en la burguesía española, Edicusa, Madrid, 1974. 


\section{CUADRO 11}

Edad media al matrimonio, 1971-2000

\begin{tabular}{|c|c|c|}
\hline Años & Varones & Mujeres \\
\hline $1971 \ldots \ldots \ldots$ & 27,15 & 25,78 \\
\hline 1975 & 26,89 & 24,16 \\
\hline 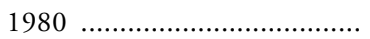 & 26,20 & 23,62 \\
\hline 1985 & 27,40 & 24,77 \\
\hline 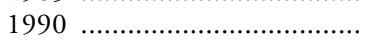 & 28,23 & 25,76 \\
\hline 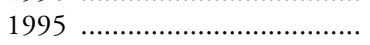 & 29,85 & 27,47 \\
\hline 2000 & 30,18 & 28,12 \\
\hline
\end{tabular}

Fuente: Movimiento Natural de la Población, años correspondientes, INE.

Y, por extensión, algo similar cabe decir respecto a la regulación de las relaciones heterosexuales de los jóvenes, y en especial de la mujer, porque detrás de ellas se esconden factores sociales, económicos, religiosos y culturales. En la medida en que estos factores se han quebrado en las sociedades modernas y lo han hecho con la misma celeridad con la que ha cambiado la sociedad española, las normas por las que se regían se han ido disolviendo, con mayor o menor rapidez, hasta llegar a ser, en muchos casos, tan sólo un recuerdo histórico de comportamientos que eran usuales una o dos generaciones atrás.

Un factor especialmente relevante para entender las nuevas pautas de conducta en este campo es el estatus de los jóvenes en la sociedad actual. El paso de la infancia a la vida adulta no ha sido tan problemático antes, porque coincidía la edad de la pubertad con el término de la etapa de formación, la fundación de la familia de procreación y el comienzo de la actividad laboral, todo lo cual traía consigo la participación plena en la vida social de la comunidad. Hoy, en cambio, la pubertad abre a menudo para los jóvenes un largo periodo dedicado al estudio y la integración en la vida laboral no se les presenta demasiado fácil.

En la actualidad, incluso la palabra noviazgo está desfigurada, cuando no proscrita, en el lenguaje de la juventud, que simboliza así su ruptura con cualquier formalización de las relaciones prematrimoniales. Hasta el mismo matrimonio aparece vaciado de significación ritual. Las relaciones sexuales prematrimoniales están difundidas y son aceptadas de forma bastante general, en abierto contraste con la sanción moral y legal que merecían en otras épocas. La mujer ha adquirido una gran libertad y una igualdad plena con el hombre en este terreno, aunque subsistan diferencias entre los sexos en cuanto a determinados comportamientos y actitudes.

El común denominador de los cambios operados en nuestro país en este ámbito comprende una liberalización de las conductas, una permisividad de las 
transgresiones de las normas y pautas anteriores, y un aumento del escepticismo y el relativismo con los que se encaran las instituciones del matrimonio y del noviazgo, así como las ceremonias, los compromisos, la virginidad y las relaciones sexuales, los factores económicos en la elección del cónyuge y otros aspectos de la relación. Todo esto afecta principalmente a los jóvenes, pero de alguna forma también a la sociedad entera. Parece como si las normas morales que regían las relaciones de pareja se hubieran flexibilizado para poder cumplir las funciones que han de desempeñar en las sociedades actuales, aunque no hayan desaparecido totalmente los valores tradicionales subyacentes a esta clase de relaciones: amor romántico, fidelidad e intención de casarse y formar una familia.

Hoy contamos con bastantes datos de encuestas sobre las opiniones de la población española acerca de estos temas, aunque no todos sean fiables y menos aún comparables, a causa de las diferentes metodologías con las que se han obtenido. De su examen se deducen algunas tendencias destacadas ${ }^{18}$. En primer lugar, que las relaciones sexuales prematrimoniales tienden a ser aceptadas de manera bastante general por los jóvenes, aunque preferiblemente cuando existe un compromiso para casarse o enamoramiento (65 y 67\% para mujeres y hombres, respectivamente), en claro contraste con lo que piensan las personas mayores, de 60 y más años, que raramente aprueban tales relaciones (entre un 11 y un 15\%). El CIRES precisó en 1990 que el 57\% de los españoles piensan que las relaciones prematrimoniales íntimas no son "deseables».

A partir de una encuesta realizada en 1995 por el Centro de Investigaciones Sociológicas titulada Actitudes y conductas interpersonales de los españoles ante el plano afectivo, podemos hacer referencia a las cuestiones que veníamos comentando respecto al noviazgo y al matrimonio. Existe un gran acuerdo en la población española acerca de lo que se entiende por relación de pareja. Un $76 \%$ opina que una relación de pareja es aquella que se mantiene en el tiempo, en la que existen sentimientos y en la que se practican relaciones sexuales. Sin embargo, la nota característica para entenderla radica en que un $15 \%$ de los jóvenes, frente a un 5\% de los mayores, la consideran una simple relación sexual esporádica como relación de pareja ${ }^{19}$. Sin embargo, muchos aspectos tradicionales como la fidelidad, la creencia en el destino o el amor como garantía de la pareja siguen gozando de importancia en las relaciones de pareja $(83,52$, $76 \%$, respectivamente). El amor como base de las relaciones de pareja y como fuerza favorable a su mantenimiento sigue considerándose importante: un $67 \%$ de la población considera que una relación verdadera debe durar toda la vida y un $76 \%$ estima que el amor verdadero lo puede todo. Además, a medida que aumenta la edad, el grado de acuerdo con estas proposiciones es mayor ${ }^{20}$.

18 S. del Campo y M. Navarro, op. cit., p. 99.

19 Actitudes y conductas interpersonales de los españoles ante el plano afectivo, Estudio 2157, CIS, 1995. Elaboración propia.

${ }^{20}$ Ibidem. 
Otra de las transformaciones recientes ha sido la pérdida de importancia del factor económico en la elección del cónyuge. El carácter de la otra persona (73\%), la fidelidad (71\%), las creencias sobre la vida (66\%), tres aspectos que están relacionados con la compatibilidad de caracteres, son las cualidades más comunes a la hora de seleccionar a la pareja. El 37\% de las parejas, según esta misma encuesta, sopesó si él y ella formaban una pareja compatible.

Por lo que toca a la evolución que han podido experimentar estas características o cualidades a lo largo del tiempo, se puede afirmar que la importancia otorgada al carácter, a las creencias y a la fidelidad no ha sufrido alteraciones, y siempre ha sido importante. Sí podemos concretar, sin embargo, que los grupos de mayor edad valoran más que los jóvenes las siguientes cualidades: que la pareja sea más joven, la situación económica de la pareja y un mayor deseo de contraer matrimonio, formar una familia y tener hijos.

Estas diferencias se pueden entender mejor si las analizamos según el sexo: las mujeres prefieren más todas las características mencionadas que los hombres, excepto la diferencia de edad de la pareja: la mujer prefiere que la pareja sea mayor que ella y el hombre prefiere que la mujer sea más joven. Por otro lado, el hombre no se fija tanto en el aspecto económico como la mujer, lo que evidencia en parte quién es todavía el principal aportador de ingresos en las parejas $^{21}$.

La gran revolución en la liberalización de las conductas ha sido la mayor permisividad en las relaciones sexuales de la población española. Aunque éstas no legitiman actualmente el matrimonio sin estar enamorado (19\% de la población española lo legitima), ni el matrimonio sin deseo sexual (19\%), ni las relaciones amorosas sin atracción sexual (33\%), podemos considerar que actualmente la práctica sexual adquiere sentido por sí misma, convirtiéndose en uno de los requisitos del funcionamiento y pervivencia de la relación de pareja, sin que ello signifique que no se pueda ejercer fuera de las relaciones de pareja. El 48\% de la población aprueba la idea de tener relaciones sexuales sin sentir amor, pero no en una relación de pareja, es decir, la falta de amor se legitima por las generaciones más jóvenes únicamente en las relaciones sexuales esporádicas.

Un $70 \%$ está de acuerdo con la idea de que se puede amar romántica e intensamente a una persona y no tener ningún propósito de contraer matrimonio con ella. A pesar de que casarse sea la forma de convivencia ideal, se abre la posibilidad de otras opciones de vida, como permanecer solteros, sin poner en duda la autenticidad de los sentimientos de y hacia la pareja.

En todo este proceso, las mujeres adoptan actitudes más tradicionales que los hombres, a pesar de los cambios generales que se producen en las actitudes y en los comportamientos. El hombre sigue manteniendo la actitud de ser más promiscuo y permisivo que las mujeres. Existe una gran diferencia entre los hombres y las mujeres que consideran que se pueden tener relaciones sin amor

\section{${ }^{21}$ Ibidem.}


(64\% frente al $14 \%)$ y en la permisividad de las relaciones prematrimoniales (72\% frente a $67 \%)$. Para la mujer, el fin último si hay amor es el matrimonio (28\% hombres y $33 \%$ mujeres).

La mujer es más permisiva que en épocas anteriores, de acuerdo con los cambios acontecidos en la sociedad, pero adopta la actitud de practicar las relaciones sexuales en un contexto de amor y de perspectiva de futuro. Connell utilizó el concepto de exaggerated feminity para aludir al hecho de que «el sexo ocurre para la mujer en el contexto de estar enamorada y (ser dependiente) de un hombre ${ }^{22}$. En consecuencia, hemos pasado de preguntarnos si el sexo es pecado a cómo conseguir con él la mayor satisfacción ${ }^{23}$.

Por otra parte, las conductas de los jóvenes parecen concordar con sus opiniones, ya que una mayoría creciente, según las distintas encuestas disponibles, ha mantenido relaciones sexuales, sobre todo por encima de los dieciocho años. Datos del Primer Congreso de la Federación Española de Sociedades de Sexología indican que el $24 \%$ de los chicos y el 12\% de las chicas habían mantenido relaciones sexuales completas antes de los dieciséis años y que, como consecuencia de ellas y de la carencia de educación sexual, los embarazos no deseados entre las menores de dieciochos años eran ya comparativamente más en España en 1978 que en ningún otro país europeo. En 1985 hubo nada menos que 29.586 nacimientos entre mujeres menores de veinte años y 5.941 entre las que aún no habían cumplido los dieciocho años.

Otro bloque de opinión que también se ha modificado tiene que ver con las actitudes de rechazo del casamiento y de aceptación de las uniones consensuales. En este terreno se aprecia una fisura, porque existe una minoría de jóvenes (un 10\% aproximadamente) que no desean casarse nunca. La norma sigue siendo, no obstante, la aceptación del matrimonio como situación personal más deseable. Centrándonos en las metas y aspiraciones de los jóvenes, podemos afirmar que el 38\% aspira a casarse y a tener una familia y casi la mitad a tener un trabajo estable. La familia por vía matrimonial y el trabajo siguen siendo actualmente las dos vías de acceso al mundo adulto, aunque este periodo de transición se alargue en el tiempo ${ }^{24}$.

Esto no excluye una actitud de mayor permisividad hacia las uniones consensuales, que son consideradas incluso como una especie de matrimonio a prueba. Así, por ejemplo, entre la población mayor de dieciocho años un 17\% considera que deben ser fomentadas para que el matrimonio se haga con "conocimiento de causa", mientras que un $41 \%$ las entiende como un resultado de la evolución de las costumbres al que hay que acomodarse, y sólo un tercio las enjuicia como totalmente inmorales. Además, un $80 \%$ cree que el tipo de parejas que las mantienen aumentará en el futuro próximo. De todos mo-

${ }^{22}$ R. Connell, Gender and Power; Society, the Person and Sexual Politics, Ed. Cambridge with association with Blackwell, 1987.

${ }^{23}$ Actitudes y conductas interpersonales de los españoles ante el plano afectivo, Estudio 2157, CIS, 1995. Elaboración propia.

${ }^{24}$ Juventud y Economía, Estudio 2265, CIS, 1997. Elaboración propia. 
dos, la encuesta del CIRES ya mencionada revela una actitud cada vez más conservadora ante el matrimonio por parte de los jóvenes actuales, a pesar de que reconocen que es difícil encontrar la pareja ideal. Un amplio conjunto de españoles (77\%) opinan que el matrimonio no está pasado de moda, y más del $90 \%$ de los entrevistados de la misma organización en 1990 afirmaban que para ellos el primer valor es la familia, por la cual estarían dispuestos a sacrificarlo todo, mientras que el 66\% de los casados manifestaban que se jurarían de nuevo fidelidad ante el altar si llegara el caso y que les gustaría que sus hijos les imitaran.

Lo anterior se complementa con el conocimiento de la situación de pareja que se da en España. El 46,1\% de la población de diez y más años vivía en 1991 sin pareja y el resto en pareja, es decir, el 53,9\%, según la Encuesta Sociodemográfica, cuya muestra básica es de 159.154 individuos, mientras que las uniones estables eran solamente 198.978 y equivalían al 1,6\% del total de las parejas. Por otro lado, el $96 \%$ de los matrimonios seguían viviendo en una primera y única unión, frente al $62,4 \%$ de las uniones estables que se hallaban en el mismo caso.

De esto y de la menor divorcialidad que se observa en nuestro país resulta que solamente el $4 \%$ de las familias españolas son recompuestas, es decir, que están formadas por alguna persona que ha visto terminadas, o ha disuelto voluntariamente, una o más familias suyas anteriores. Y también en este punto se aprecia una diferencia notable con la situación que prevalece en otros países europeos y con la de Estados Unidos.

En cuanto a la fecundidad diferencial, el $90,6 \%$ de los matrimonios españoles tienen hijos, frente a solamente el $48,6 \%$ de las uniones maritales estables. Además, el número medio de hijos es también diferente en uno y otro tipo de unión: los matrimonios tienen 2,7 y las uniones consensuales 1,8. Esto aparece confirmado por el tomo I del Censo de Población de 1991, en el que se comprueba que de los 1,7 hijos por mujer nacidos vivos en España de mujeres de más de quince años, a las solteras correspondían 0,1 y a las no solteras 2,4. En 1999, las diferencias entre la fecundidad de los matrimonios y de las parejas cohabitantes se habían acortado. En la fecha de referencia, y tal como se muestra en el cuadro 12 , el $91 \%$ de los matrimonios tenían hijos, frente al $60 \%$ de las parejas cohabitantes.

Por otra parte, antes las relaciones sexuales no se legitimaban fuera del matrimonio y, una vez contraído éste, su fin era la procreación. De este modo, la maternidad era abrumadoramente matrimonial. Ahora, en cambio, la proporción de nacimientos extramatrimoniales es considerable y ha pasado de ser el $1,3 \%$ en 1970 a ser el $20 \%$ en $2000^{25}$.

Finalmente, el cuadro 13 reproduce una tabulación especial de la Encuesta Sociodemográfica de 1991, que relaciona la composición de los núcleos familiares españoles según la situación de pareja o monoparentalidad con el número de

25 S. del Campo, La nueva familia española, Eudema, 1992; INE, Indicadores sociales en España (1991-1996) y España en Cifras, 2002. 


\section{CUADRO 12}

\section{Fecundidad de los matrimonios/parejas cohabitantes}

\begin{tabular}{|c|c|c|}
\hline Número de hijos & Matrimonio & $\begin{array}{c}\text { Pareja estable } \\
\text { en el hogar }\end{array}$ \\
\hline 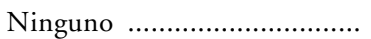 & 9,36 & 39,73 \\
\hline 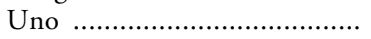 & 23,75 & 29,65 \\
\hline Dos & 46,66 & 20,10 \\
\hline 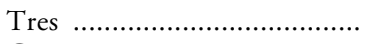 & 14,99 & 7,91 \\
\hline 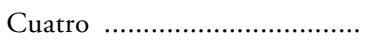 & 3,41 & 1,34 \\
\hline Cinco o más .............................. & 1,83 & 1,28 \\
\hline 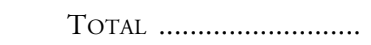 & 100 & 100 \\
\hline
\end{tabular}

FUENTE: Encuesta de Fecundidad, 1999, INE.

hijos por núcleo familiar. En él podemos comprobar que el $86 \%$ de las familias monoparentales estaban encabezadas por mujeres y que el número medio de hijos de estos hogares $(1,6)$ era superior al de todos los núcleos conyugales, que era de 1,5 , pero no al de los núcleos conyugales con hijos, que era de 2,0 , dado que el $24,3 \%$ de los matrimonios o parejas carecían de descendencia.

\section{CUADRO 13}

Núcleos familiares por número de hijos (miles), 1991

\begin{tabular}{|c|c|c|c|c|c|c|c|c|}
\hline \multirow[b]{2}{*}{ Número de hijos } & \multicolumn{2}{|c|}{$\begin{array}{l}\text { Total de } \\
\text { núcleos }\end{array}$} & \multicolumn{2}{|c|}{$\begin{array}{c}\text { Matrimonio } \\
\text { o pareja }\end{array}$} & \multicolumn{4}{|c|}{ Monoparentales* } \\
\hline & Núm. & $\%$ & Núm. & $\%$ & Total & $\%$ & $\begin{array}{l}\text { Padres } \\
\text { solos }\end{array}$ & $\begin{array}{l}\text { Madres } \\
\text { solas }\end{array}$ \\
\hline 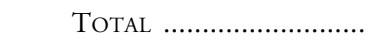 & 9.699 & 100,0 & 8.726 & 100,0 & 973 & 100,0 & 136 & 837 \\
\hline 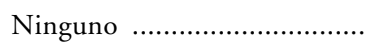 & 2.122 & 22,0 & 2.122 & 24,3 & - & - & - & - \\
\hline 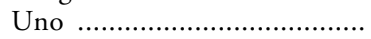 & 2.729 & 28,1 & 2.177 & 24,9 & 552 & 56,7 & 77 & 475 \\
\hline Dos & 2.978 & 30,7 & 2.712 & 31,1 & 266 & 27,3 & 39 & 227 \\
\hline 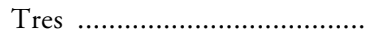 & 1.255 & 12,9 & 1.150 & 13,2 & 105 & 10,8 & 13 & 92 \\
\hline Cuatro y más .............................. & 615 & 6,3 & 565 & 6,5 & 50 & 5,2 & 7 & 43 \\
\hline $\begin{array}{l}\text { Número medio de hijos por } \\
\text { núcleo familiar }\end{array}$ & 1,54 & - & 1,53 & - & - & - & 1,63 & 1,65 \\
\hline
\end{tabular}

* El número de familias monoparentales asciende al $10 \%$ del total de núcleos, estando encabezadas por padres el 1,4 y por madres el 8,6.

FuENTE: INE, Encuesta Sociodemográfica, 1991. Tabulación especial a petición del autor. 


\section{LA PLANIFICACIÓN DE LA FAMILIA}

La mencionada drástica caída de la fecundidad española desde 1978 se ha materializado mediante decisiones privadas tomadas en el seno de la familia. En este sentido cabe hablar de la implantación de una planificación familiar, que supone un giro completo respecto de las conductas observadas en otras épocas y que conviene conocer adecuadamente.

a) La anticoncepción. Contamos para su análisis con tres encuestas sobre fecundidad realizadas a las mujeres españolas en 1977, 1985 y $1999^{26}$. De ellas se infiere que la reducción de nuestra fecundidad se ha producido justamente cuando la mayoría de las españolas han podido conocer, y sobre todo utilizar con libertad, los métodos anticonceptivos, lo cual ha sucedido después de la instauración de la democracia.

En general, podemos concluir que la población tiene un alto conocimiento de los diferentes métodos anticonceptivos, y así lo prueba que el $99 \%$ de las mujeres declara conocer al menos uno eficaz. En los años setenta estaban socialmente permitidos el coitus interruptus, el ritmo y temperatura basal y la abstinencia. Otros métodos como el preservativo, el DIU, la píldora, cremas anticonceptivas y el lavado vaginal se han ido conociendo poco a poco, llegando a ser algunos los más conocidos actualmente. El 99\% conoce la píldora y el condón, y el $91 \%$ el DIU. Un último aspecto a señalar en cuanto al conocimiento de los métodos concierne a los orientados a la esterilización de la mujer y del hombre y a la píldora del día siguiente, que, de no recogerse siquiera en la encuesta de 1977, han llegado a representar el 94, 92 y 69\% en la de 1999.

El hecho de este conocimiento, a pesar de ser decisivo, no explica por qué todavía en 1985 había un 33,5\% de mujeres que no habían utilizado nunca ningún método y un $14 \%$ que había empleado alguno ineficaz. Estos porcentajes cambian en el caso de las mujeres casadas, entre las que son el 16 y el $18 \%$, respectivamente, las que se hallan en igual situación, lo cual avala, cuando menos parcialmente, la hipótesis de que la difusión de estos medios se ha producido en los últimos años, dado que en la encuesta de 1977 el grupo de mujeres casadas que no había utilizado nunca un método se elevaba al $40 \%$.

En 1985, la relación de pareja, el estado civil, la creencia y práctica religiosa y la actividad laboral eran variables decisivas, en especial las dos primeras, para explicar el uso diferencial que las mujeres realizaban de los métodos anticonceptivos. A ellas hay que añadir otras, como la edad, el nivel de estudios, el número de hijos y la actividad laboral actual. Para decirlo con brevedad, la utilización de un determinado método está condicionada por variables objetivas, como el mantenimiento de relaciones sexuales estables y el número de hijos tenidos y, consiguientemente, la edad o el estado civil, pero también por varia-

${ }^{26}$ INE, Encuesta de Fecundidad, diciembre 1977, Madrid, 1978; Encuesta de Fecundidad, 1985, Avance de Resultados, Madrid, 1986; Encuesta de Fecundidad, 1999. 


\section{CUADRO 14}

Conocimiento de métodos anticonceptivos por mujeres en edad fértil

\begin{tabular}{|c|c|c|c|}
\hline & 1977 & 1985 & 1999 \\
\hline No conoce ningún método & 7 & 0,9 & 0,8 \\
\hline Conoce al menos uno pero no eficaz ............... & 2 & 0,4 & 0,0 \\
\hline Conoce al menos un método eficaz .................. & 91 & 99 & 99 \\
\hline Conoce píldora & 95 & 98 & 99 \\
\hline 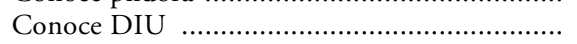 & 32 & 81 & 91 \\
\hline Conoce diafragma, tapón, esponja vaginal ....... & 21 & 57 & 78 \\
\hline Conoce abstinencia & & 70 & 81 \\
\hline 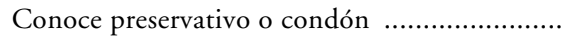 & 73 & 94 & 99 \\
\hline Conoce ritmo y temperatura basal .................... & 57 & 75 & 58 \\
\hline 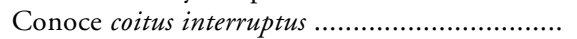 & 76 & 88 & 82 \\
\hline 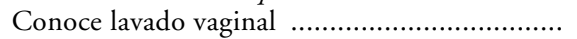 & 38 & 48 & 59 \\
\hline Conoce cremas anticonceptivas .......................... & 38 & 47 & 64 \\
\hline Conoce lactancia prolongada .............................. & 36 & 48 & 46 \\
\hline Conoce inyección & - & 62 & 52 \\
\hline Conoce píldora del día siguiente ..................... & - & 25 & 69 \\
\hline 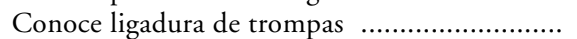 & - & 93 & 94 \\
\hline 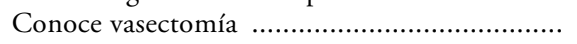 & - & 78 & 92 \\
\hline 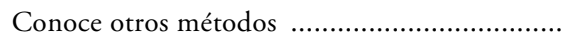 & 10 & 1 & 8 \\
\hline
\end{tabular}

Fuente: Encuesta de Fecundidad, INE, 1977, 1985 y 1999. Los datos de 1977 tienen como base las mujeres en edad fértil no solteras.

bles subjetivas, como las creencias religiosas, la historia profesional o el nivel de estudios.

En 1999, el 73\% de la población femenina expuesta al embarazo ha utilizado o utiliza algún método anticonceptivo. Las mujeres que lo hacen son, en su mayoría, las casadas, separadas y divorciadas y aquellas que mantienen una pareja estable, las no creyentes y las que no se dedican a trabajar, si bien más de la mitad de las mujeres que trabajan ponen medios para no concebir.

Respecto al método utilizado según diferentes características de las mujeres, observando el cuadro 15 podemos concluir que los dos más utilizados son la píldora y el preservativo (31 y 34\%, respectivamente). En 1999 las pautas de utilización de los métodos anticonceptivos se mantienen, pero hay que centrarse en dos que adquieren importancia no tanto por su cuantía, sino porque cuando aparecen en la Encuesta de Fecundidad es en 1999.

Tanto el perfil de las mujeres que se esterilizan con la ligadura de trompas como el de las mujeres de los hombres que se hacen la vasectomía son muy similares. En la mayoría de los casos son mujeres casadas, católicas no practicantes y que se dedican a sus labores, ya que el método anticonceptivo que más utilizan las mujeres trabajadoras son el DIU y el preservativo, y las mujeres no creyentes, la píldora y el preservativo. 


\section{CUADRO 15}

Utilización de métodos anticonceptivos

\begin{tabular}{|c|c|c|c|c|c|c|c|}
\hline & $\begin{array}{c}\text { Ha utilizado } \\
\text { o utiliza } \\
\text { actualmente }\end{array}$ & Pildora & $D I U$ & Preservativo & Retiro & $\begin{array}{l}\text { Ligadura } \\
\text { de trompas }\end{array}$ & Vasectomía \\
\hline TOTAL …........................... & 73 & 31 & 7 & 34 & 10 & 4 & 4 \\
\hline 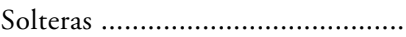 & 49 & 44 & 10 & 41 & 22 & 1 & 2 \\
\hline 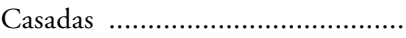 & 91 & 52 & 82 & 57 & 75 & 90 & 97 \\
\hline 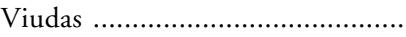 & 84 & 0 & 1 & 0 & 1 & 1 & 0 \\
\hline Separadas/Divorciadas ................. & 93 & 3 & 7 & 2 & 2 & 6 & 1 \\
\hline 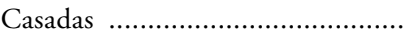 & 91 & 52 & 82 & 57 & 75 & 90 & 97 \\
\hline Unión estable en el hogar ............ & 95 & 8 & 9 & 4 & 5 & 3 & 2 \\
\hline Unión estable sin el hogar ............ & 75 & 30 & 2 & 28 & 16 & 1 & 1 \\
\hline Sin unión estable...$\ldots \ldots \ldots \ldots \ldots \ldots \ldots \ldots$ & 75 & 3 & 2 & 7 & 3 & - & - \\
\hline No creyente ............................. & 0 & 8 & 4 & 5 & 3 & 3 & 5 \\
\hline Católica no practicante ............... & 13 & 58 & 56 & 55 & 42 & 49 & 52 \\
\hline Católica practicante $. . . \ldots \ldots \ldots \ldots \ldots \ldots . . . . . .$. & 21 & 24 & 28 & 30 & 46 & 38 & 36 \\
\hline Ocupadas por cuenta propia ....... & 30 & 8 & 12 & 7 & 8 & 11 & 9 \\
\hline Ocupadas asalariadas fijas ............ & 21 & 23 & 28 & 23 & 25 & 21 & 22 \\
\hline 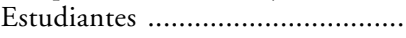 & 1 & 10 & 1 & 13 & 3 & 1 & 1 \\
\hline Labores del hogar ........................ & 63 & 23 & 35 & 26 & 38 & 43 & 43 \\
\hline
\end{tabular}

FuENTE: Encuesta de Fecundidad, 1999, INE. 
Como conclusión de lo dicho cabe establecer que la planificación familiar española se va acercando paulatinamente a la que existe en otros países europeos, siendo su perfil aproximado el que sigue: han utilizado y utilizan en la actualidad métodos anticonceptivos las mujeres que han estado o están en los niveles superiores del sistema educativo, las que habitan en las zonas más urbanizadas, las que se declaran no creyentes, las mujeres más jóvenes y las que se casan más jóvenes, las que ya tienen dos o tres hijos, las que han trabajado y, sobre todo, las que están estudiando.

Conviene advertir, en fin, que más de la mitad de las mujeres no solteras que utilizan actualmente anticonceptivos emplean métodos ineficaces, lo cual tiene que ver sin duda con su defectuoso conocimiento de esta materia, pese a la despenalización de los anticonceptivos aprobada tras la democracia y a la apertura de centros de planificación familiar en diversas ciudades españolas. Hay factores culturales, religiosos y de ignorancia y tradición que impregnan las actitudes y los comportamientos de las mujeres en este y otros asuntos relacionados con la familia, y también pasa lo mismo con los hombres, aunque en un grado menor.

b) El aborto. Uno de los temas más controvertidos moralmente en nuestra sociedad es la aprobación y práctica del aborto. En este punto debemos distinguir dos cuestiones. Por una parte, y según Margarita Delgado ${ }^{27}$, la interrupción voluntaria del embarazo, bajo los tres supuestos que ampara la Ley de 1985, no ha dejado de aumentar en la década de los noventa, en la cual las estadísticas son más fiables, aunque no se registren todos los abortos que se realizan.

A partir de los datos facilitados por el Ministerio de Sanidad y Consumo, el número de abortos pasó de ser 44.962 en el año 1992 a ser casi 70.000 en el año 2001, produciéndose un aumento del $9 \%$ en este último año respecto al anterior. La tasa actual de interrupciones por cada 1.000 mujeres es de 7,66. Sin embargo, este comportamiento no es uniforme en los diferentes tramos de edad: el grupo que más lo practica es el de 20-24 años, que alcanza una tasa de 12,86 , aunque resulta llamativo y preocupante que entre las mujeres menores de 19 años haya aumentado de 3,9 en 1992 a 8,29 en 2001.

El motivo más frecuentemente mencionado por las mujeres que interrumpieron un embarazo en 2001 fue el riesgo para su salud (97,1\%), que fue alegado por el $98,4 \%$ de las mujeres que se sometieron a esta clase de intervención. Paralelamente a este descenso, ha aumentado el peso de los abortos por riesgo para el feto (2,5\% de los casos en 2001 frente a $1,4 \%$ en 1992) y ha subido ligeramente el porcentaje de abortos por violación, que sigue siendo el de menor incidencia (0,09\% en 2001 y 0,02 en 1992).

El aborto no es practicado por igual en toda la geografía española. Balea-

27 M. Delgado, «Familia y Fecundidad en España», Arbor, CLXXIV, 685 (enero 2003), pp. 21-34. 
res, Madrid y Cataluña son las Comunidades con más altas tasas $(13,21,10,47$ y 10,18, respectivamente), y Melilla, País Vasco y Extremadura las que las tienen más bajas $(3,21,3,55 \text { y 3,61, respectivamente })^{28}$.

Actualmente, más de seis de cada diez interrupciones voluntarias se practican en las primeras ocho semanas de gestación. Sin embargo, según los datos facilitados por el Ministerio de Sanidad y Consumo (cuadro 16), desde 1992 a 2001 ha aumentado el porcentajes de interrupciones que se producen cuando la gestación está más avanzada. Así, si en 1992 el porcentaje de interrupciones en 13-16 semanas, 17-20 semanas y 21 o más semanas fue de 2,67, 1,43 y 0,38, en 2001 los porcentajes fueron 5,25, 3,68 y 1,67, respectivamente.

\section{CUADRO 16}

Número de centros que han notificado IVE, número de abortos realizados $y$ tasas por 1.000 mujeres entre 15-44 años

\begin{tabular}{|c|c|c|c|c|}
\hline & Años & $\begin{array}{c}\text { Centros } \\
\text { notificadores } \\
\text { de IVE }\end{array}$ & $\begin{array}{l}\text { Número } \\
\text { de abortos }\end{array}$ & Tasas \\
\hline 2001 & ................... & 121 & 69.857 & 7,66 \\
\hline 2000 & . & 121 & 63.756 & 7,14 \\
\hline 1999 & 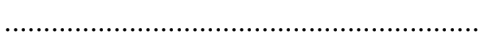 & 123 & 58.399 & 6,52 \\
\hline 1998 & 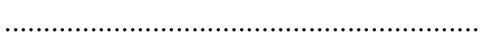 & 117 & 53.847 & 6,00 \\
\hline 1997 & . & 115 & 49.578 & 5,52 \\
\hline 1996 & . & 106 & 51.002 & 5,69 \\
\hline 1995 & 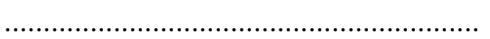 & 102 & 49.367 & 5,53 \\
\hline 1994 & . & 101 & 47.832 & 5,38 \\
\hline 1993 & . & 95 & 45.503 & 5,15 \\
\hline 1992 & . & 87 & 44.962 & 5,10 \\
\hline
\end{tabular}

Fuente: Ministerio de Sanidad y Consumo, Estadisticas Sanitarias.

Según muestran los anuarios estadísticos de 1950 a 2000, el número de abortos terapéuticos ha descendido considerablemente (cuadro 17). El ritmo de descenso se aceleró a partir de 1970, cuando sólo pasaron a considerarse abortos las muertes fetales tardías, es decir, los nacidos muertos con más de seis meses. Este descenso puede deberse a la mayor información y asistencia médica en nuestro país y a la propia evolución de las interrupciones voluntarias de embarazos desde su despenalización limitada en 1985.

${ }^{28}$ Ministerio de Sanidad y Consumo, Estadísticas Sanitarias, Madrid, 2001. 


\section{CUADRO 17}

Número de abortos terapéuticos y tasas de abortividad

\begin{tabular}{|c|c|c|c|}
\hline & Años & $\begin{array}{l}\text { Número } \\
\text { de abortos } \\
\text { terapéuticos }\end{array}$ & $\begin{array}{c}\text { Tasas de } \\
\text { abortividad }\end{array}$ \\
\hline 1950 & $\ldots \ldots \ldots \ldots \ldots \ldots \ldots$ & 18.940 & 0,66 \\
\hline 1955 & 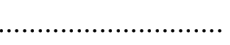 & 21.920 & 0,76 \\
\hline 1960 & 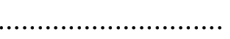 & 24.140 & 0,80 \\
\hline 1965 & $\ldots$ & 20.779 & 0,66 \\
\hline 1970 & ......................... & 16.810 & 0,50 \\
\hline 1975 & ........................ & 7.584 & 0,21 \\
\hline 1980 & ........................ & 6.767 & 0,18 \\
\hline 1985 & 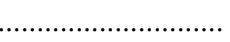 & 2.907 & 0,08 \\
\hline 1990 & .......................... & 1.617 & 0,04 \\
\hline 1995 & .......................... & 1.254 & 0,03 \\
\hline $2000^{*}$ & 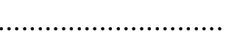 & 1.439 & 0,04 \\
\hline
\end{tabular}

Fuente: Anuario Estadístico. A partir del año 1975 sólo se incluyen las muertes fetales tardías, es decir, los nacidos muertos con más de seis meses.

\section{LAS RELACIONES FAMILIARES}

Las relaciones entre los miembros de la familia forman la trama habitual en la que se desarrolla su convivencia y de ellas vamos a considerar, en primer lugar y fundamentalmente, las relaciones de pareja — es decir, las que se establecen entre los cónyuges en sus distintas facetas: igualdad, afectividad, convivencia y conflictividad- y, en segundo lugar, las paterno-filiales.

\section{Relaciones de igualdad}

Seguramente, la igualdad de ambos cónyuges dentro de la familia es uno de los aspectos en los que más se ha avanzado en los últimos años, aunque hay que diferenciar varias dimensiones si no se desea falsear la verdadera situación. En cualquier caso, el estatus de la mujer en la sociedad y en la familia moderna ha experimentado una transformación muy apreciable, provocada en gran parte por el aumento de su nivel educativo, que le ha facilitado la entrada en el mercado laboral y ha cambiado asimismo la imagen que se tiene de su papel. La evolución de las tasas de matriculación universitaria ha sido sorprendente: de ser un 15\% de las matrículas en 1950-51 han llegado actualmente al 59\% en $2000^{29}$. Este comportamiento es paralelo, aunque no de la misma cuantía,

29 Hasta curso 1988-89, Anuarios Estadisticos correspondientes. Dato 2000, Indicadores Sociales, 2000, INE. 
al de su entrada en el mercado laboral, en el que la tasa de actividad de la mujer alcanza actualmente el $40 \%{ }^{30}$. Los movimientos feministas y los medios de comunicación han influido decisivamente en este cambio, pero la democratización de la vida social y las nuevas condiciones que han facilitado la incorporación de la mujer a los centros de estudio y a la actividad laboral, junto con un hogar más sencillo de llevar y más tecnificado, son factores que han colaborado mucho para hacer posible la salida de la mujer al exterior desde la vida doméstica.

Este proceso se puede calificar de gran tendencia de la sociedad actual, pero si descendemos al terreno microsociológico comprobamos que en él las tradiciones siguen teniendo un protagonismo destacado. De ahí que las diferencias por sexo y, sobre todo, por edad sean decisivas para diferenciar las opiniones y actitudes acerca de la desigualdad y, más aún, los comportamientos. Por ejemplo, una elevada proporción de personas adscriben aún tareas y estereotipos específicos a la mujer: las faenas de la casa o la educación de los niños, junto a imágenes que acentúan el cuidado del propio aspecto físico antes que el desarrollo intelectual, o las limitaciones para trabajar fuera de casa, de las que una de las más relevantes es la existencia de un discurso en nuestra sociedad a partir del cual se legitima el trabajo extradoméstico de la mujer ${ }^{31}$. El cuadro 18 recoge la aceptación del trabajo extradoméstico de la mujer en función de tener o no hijos y del tipo de jornada laboral y, de acuerdo con él, podemos concluir que la crianza de los hijos supone un obstáculo importante en la opinión para el desarrollo profesional de la mujer. Se da una gran aceptación del trabajo de la mujer cuando no está casada y no tiene hijos y una vez que los hijos se han independizado ( 72 y $75 \%$ de la población, respectivamente).

En cuanto a trabajar dependiendo de la edad de los hijos, la percepción de las cosas cambia. El 38\% de la población no aprueba que la mujer vaya a trabajar cuando los niños aún no tienen edad de ir a la escuela, y este porcentaje disminuye al $13 \%$ cuando los hijos empiezan a ir a la escuela. Todo esto, con el matiz de que lo que se aprueba es el trabajo a tiempo parcial. Por otra parte, es interesante conocer la actitud de los hombres, ya que ellos son los que tradicionalmente han salido a trabajar.

La importancia que la mujer otorga a los hijos a la hora de trabajar la podemos examinar o ver desde la vertiente contraria, es decir, considerando hasta qué punto las mujeres trabajadoras están dispuestas a tener hijos o no. Los datos de la Encuesta de Fecundidad de 1999 son bastante significativos. En ella vemos que, a medida que la condición laboral de la mujer está más estabilizada, la intención de tener hijos es menor $(51,84 \%)$, tendencia que choca con las mujeres que están paradas y buscan un empleo y las estudiantes $(59,88$ y 92,37\%, respectivamente). Queda claro que la situación laboral de la mujer influye, pero la decisión de tener hijos está condicionada también por otros

${ }^{30}$ Encuesta de Población Activa, años correspondientes, INE.

${ }^{31}$ S. del Campo y M. Navarro, op. cit., pp. 137-145. 


\section{CUADRO 18}

Aceptación del trabajo extradoméstico de la mujer

\begin{tabular}{|c|c|c|c|}
\hline & Hombres & Mujeres & Total \\
\hline \multicolumn{4}{|l|}{ Después de casarse y antes de tener hijos } \\
\hline 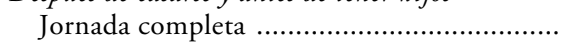 & 69 & 74 & 72 \\
\hline 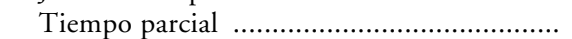 & 14 & 16 & 15 \\
\hline 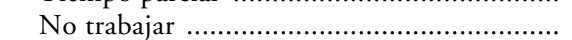 & 9 & 5 & 7 \\
\hline 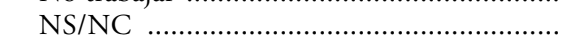 & 7 & 5 & 6 \\
\hline \multicolumn{4}{|l|}{$\begin{array}{l}\text { Cuando hay un hijo que no tiene edad para ir } \\
\text { a la escuela }\end{array}$} \\
\hline 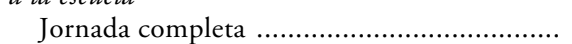 & 16 & 16 & 16 \\
\hline Tiempo parcial .......................................... & 35 & 40 & 37 \\
\hline 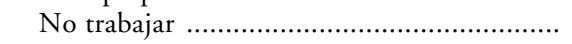 & 42 & 38 & 40 \\
\hline 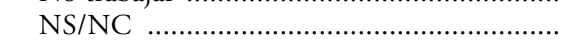 & 7 & 7 & 7 \\
\hline \multicolumn{4}{|l|}{$\begin{array}{l}\text { Después de que el hijo más pequeño haya } \\
\text { empezado a ir a la escuela }\end{array}$} \\
\hline 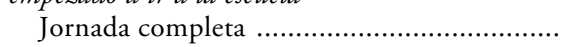 & 41 & 41 & 41 \\
\hline 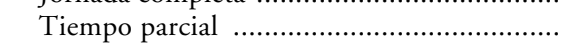 & 35 & 42 & 39 \\
\hline 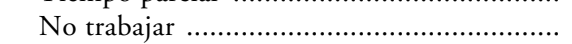 & 16 & 10 & 13 \\
\hline 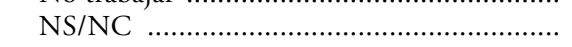 & 8 & 6 & 7 \\
\hline \multicolumn{4}{|l|}{ Después de que los hijos se hayan ido de casa } \\
\hline 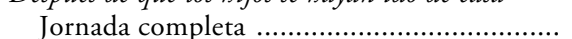 & 74 & 77 & 75 \\
\hline 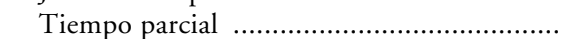 & 9 & 12 & 11 \\
\hline 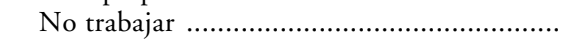 & 10 & 6 & 8 \\
\hline NS/NC & 7 & 6 & 6 \\
\hline
\end{tabular}

Fuente: Datos de Opinión, n.o 10, Centro de Investigaciones Sociológicas, 1997, p. 7.

factores como la edad de la mujer, las condiciones de trabajo o el deseo de tenerlos. Respecto a este último aspecto, los principales motivos para no tener hijos, aun deseándolos, son la falta de recursos económicos y la necesidad de aportar un ingreso adicional al hogar $\left(31\right.$ y $15 \%$, respectivamente) ${ }^{32}$.

Aceptada o no la participación de la mujer en el mercado laboral, la única realidad es que existe y que la mujer se va haciendo hueco en ese mercado tanto a nivel cuantitativo como cualitativo. Del aspecto cuantitativo ya se ha hablado, mientras que, por lo que toca al nivel cualitativo, la mujer empieza a acceder a determinados puestos de trabajo que antes le estaban vetados social y legalmente.

A partir de los datos del Movimiento Natural de la Población en tres años determinados: 1980, 1990 y 2000, recogidos en el cuadro 19, podemos con-

32 Encuesta de Fecundidad, 1999, INE. 


\section{CUADRO 19}

Matrimonios por profesión u ocupación principal de la esposa y profesión u ocupación principal del esposo

\begin{tabular}{|c|c|c|c|c|c|c|}
\hline & \multicolumn{2}{|c|}{1980} & \multicolumn{2}{|c|}{1990} & \multicolumn{2}{|c|}{2000} \\
\hline & Esposo & Esposa & Esposo & Esposa & Esposo & Esposa \\
\hline Profesionales, técnicos y trabajos asimilados ............ & 13 & 8 & 15 & 16 & 16 & 18 \\
\hline $\begin{array}{l}\text { Personal directivo de la Administración Pública y de } \\
\text { empresas }\end{array}$ & 0 & 0 & 1 & 0 & 2 & 1 \\
\hline 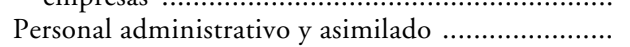 & 13 & 13 & 11 & 16 & 8 & 15 \\
\hline 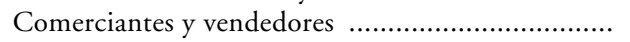 & 7 & 5 & 9 & 7 & 7 & 8 \\
\hline 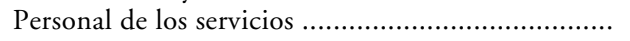 & 6 & 5 & 10 & 9 & 9 & 11 \\
\hline Agricultores, ganaderos, arboricultores, pescadores & & & & & & \\
\hline 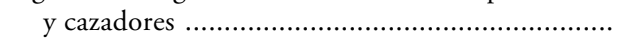 & 9 & 0 & 6 & 1 & 3 & 1 \\
\hline $\begin{array}{l}\text { Trabajadores de la producción, conductores y peo- } \\
\text { nes no agrarios }\end{array}$ & 46 & 11 & 39 & 8 & 30 & 7 \\
\hline 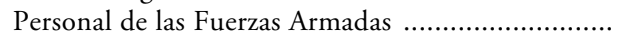 & 2 & - & 1 & 0 & 1 & 0 \\
\hline Estudiantes & 3 & 5 & 1 & 5 & 0 & 2 \\
\hline Labores del hogar & - & 51 & & 32 & 0 & 12 \\
\hline 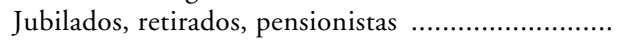 & 0 & 0 & 1 & 0 & 1 & 0 \\
\hline 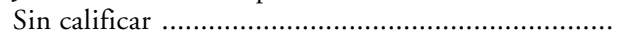 & 2 & 1 & 6 & 50 & 22 & 24 \\
\hline TOTAL & 100 & 100 & 100 & 100 & 100 & 100 \\
\hline
\end{tabular}

Fuente: Movimiento Natural de la Población, 1980, 1990 y 2000. 
cluir que se ha producido un aumento considerable de los matrimonios en los que antes solamente trabajaba el marido y ahora lo hacen los dos. Si en 1980 el 51\% de las mujeres se dedicaban a las labores del hogar, en el 2000 este porcentaje había caído más de la mitad. Aunque a priori tal caída puede parecer brusca, hay que considerar que aumentan casi un $23 \%$ las mujeres que no especifican sus cualificaciones. Respecto al tipo de ocupación que desempeñan, es difícil desprenderse de algunos estereotipos que han venido marcando la situación de la mujer. Entre los profesionales, técnicos y trabajos asimilados, comerciantes y vendedores, las diferencias son mínimas. Sin embargo, la mujer tiene una gran presencia en la rama de personal administrativo y en el sector servicios, mientras que el hombre posee casi el monopolio en las Fuerzas Armadas y entre los trabajadores de la producción, los conductores y los peones no agrarios.

\section{La toma de decisiones}

Más significativa es todavía la evolución observada en cuanto a la democratización de las relaciones de la pareja, medida a partir de la toma de decisiones, tal como se recoge en el cuadro 20, donde se comparan los resultados de tres encuestas que ponen de relieve el cambio producido en las relaciones entre los esposos desde 1966 a 1980.

$\mathrm{Si}$ atendemos a los datos para el grupo de edad de dieciocho a veintinueve años, comprobamos que la mencionada democratización de la familia, en tanto en cuanto se traduce en compartir la toma de decisiones, es casi general, al menos por lo que toca a las cuestiones más cotidianas. Además, esta democratización parece haber calado en la mayoría de los matrimonios, independientemente de su edad y en correspondencia con la tendencia hacia la transformación de la familia patriarcal en otra más igualitaria. En 1995, el 64\% de las decisiones se tomaban conjuntamente ${ }^{33}$.

La incorporación de la mujer al trabajo ha abierto el debate sobre su doble jornada laboral, ya que no sólo tiene que hacer frente al trabajo extradoméstico, sino también regir el ámbito doméstico con muy poca ayuda masculina. De ahí que sea examinando el cumplimiento de estas tareas donde mejor se pueden apreciar los cambios experimentados en el seno de las familias. Por ejemplo, ahora se observa una progresiva implicación del hombre en las tareas del hogar: el $21 \%$ prepara el desayuno o ayuda a hacerlo; el $11 \%$ friega los platos; el $15 \%$ da de comer a los niños, y el $9 \%$ limpia la casa. Obviamente, se trata de porcentajes muy pequeños, pero siluetean una evolución que se ve aún mejor si consideramos la variable edad (los mismos ítems en el grupo de dieciocho a veintinueve años arrojan los porcentajes siguientes: $33,23,30,20$ ).

${ }_{33}$ Actitudes y conductas interpersonales de los españoles ante el plano afectivo, Estudio 2157, CIS, 1995. Elaboración propia. 
CUADRO 20

Toma de decisiones en la familia, 1966, 1979 y 1980

\begin{tabular}{|c|c|c|c|c|c|c|c|}
\hline \multirow{3}{*}{$\begin{array}{c}\text { ¿Quién toma la decisión } \\
\text { final sobre...? }\end{array}$} & \multirow{3}{*}{$\begin{array}{l}\text { Muestra } \\
\text { nacional } \\
\text { (1966) }\end{array}$} & \multirow{3}{*}{$\begin{array}{c}\text { Muestra } \\
\text { mujeres } \\
18 \text { a } 29 \text { años } \\
\text { Madrid (1979) }\end{array}$} & \multicolumn{5}{|c|}{ Muestra nacional, mayores de 18 años (1980) } \\
\hline & & & \multicolumn{5}{|c|}{ Grupos de edad (años) } \\
\hline & & & Total & 18 a 29 & 30 a 44 & 45 a 59 & 60 y más \\
\hline \multicolumn{8}{|l|}{ El dinero que se gasta en alimentos } \\
\hline 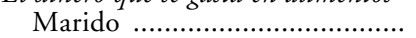 & 13 & 5 & 4 & 1 & 5 & 4 & 5 \\
\hline 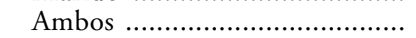 & 6 & 35 & 38 & 51 & 39 & 34 & 34 \\
\hline Mujer $\ldots \ldots \ldots \ldots \ldots \ldots \ldots \ldots \ldots \ldots \ldots \ldots$ & 75 & 59 & 54 & 45 & 53 & 58 & 54 \\
\hline \multicolumn{8}{|l|}{ 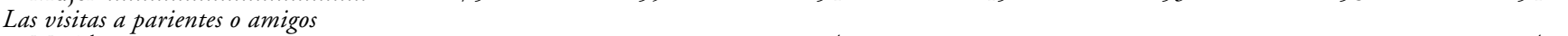 } \\
\hline Marido ...................................... & 21 & 7 & 4 & 3 & 5 & 3 & 4 \\
\hline Ambos ................................... & 35 & 76 & 80 & 86 & 83 & 80 & 70 \\
\hline Mujer & 35 & 14 & 11 & 8 & 8 & 12 & 15 \\
\hline \multicolumn{8}{|l|}{$\begin{array}{l}\text { La compra de ciertos objetos caros: } \\
\text { muebles, televisión, coche }\end{array}$} \\
\hline 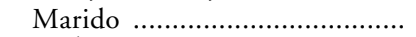 & 34 & 9 & 15 & 10 & 16 & 15 & 14 \\
\hline 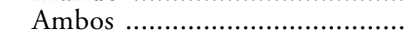 & 21 & 70 & 75 & 83 & 77 & 75 & 67 \\
\hline Mujer & 40 & 19 & 6 & 5 & 4 & 7 & 7 \\
\hline \multicolumn{8}{|l|}{ Llamar al médico si alguien } \\
\hline \multicolumn{8}{|l|}{ de la familia enferma } \\
\hline 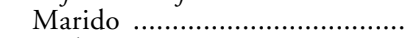 & 21 & 6 & 6 & 6 & 6 & 6 & 7 \\
\hline Ambos ..................................... & 26 & 56 & 70 & 74 & 70 & 70 & 70 \\
\hline Mujer & 46 & 36 & 19 & 16 & 21 & 21 & 14 \\
\hline \multicolumn{8}{|l|}{ Qué van a hacer los dias de fiesta.................. } \\
\hline 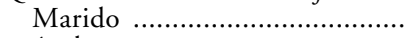 & 45 & 10 & 5 & 4 & 6 & 5 & 6 \\
\hline Ambos $\ldots \ldots \ldots \ldots \ldots \ldots \ldots \ldots \ldots \ldots \ldots$ & 26 & 70 & 80 & 89 & 82 & 80 & 71 \\
\hline Mujer ...................................... & 22 & 19 & 7 & 5 & 7 & 8 & 8 \\
\hline 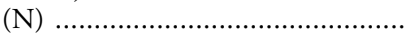 & 1.963 & 2.013 & 1.643 & 204 & 630 & 496 & 312 \\
\hline
\end{tabular}

NotA: En la encuesta de 1966, para el 21\% de los encuestados no procedía hacer la pregunta, por diversas razones. El último ítem, en 1966 y 1979 , era "¿Quién decide con qué matrimonio (otras personas) van a salir?».

FUENTES: Encuesta sobre «La estructura de autoridad en la familia española», dirigida por Salustiano del Campo, REOP, n. ${ }^{\circ} 6$, octubre-diciembre 1966, pp. 401-410; encuesta "Dinámica de la familia urbana española», inédita, y "Encuesta sobre la familia española", inédita, dirigidas ambas por Salustiano del Campo. 
Recientemente, Iglesias de Ussel ${ }^{34}$ y sus colaboradores han completado las comparaciones establecidas en el cuadro anterior, examinando la evolución de los mismos ítems entre 1980 y 1990 y comprobando, una vez más, la existencia de una mayor implicación del hombre en las tareas domésticas ${ }^{35}$.

Una encuesta reciente que refleja la situación real de los hogares españoles en este aspecto es la Encuesta de Compatibilización Familia-Empleo, realizada en 1998 por Constanza Tobío ${ }^{36}$, algunos de cuyos datos se recogen en el cuadro 21. Según esta autora, no hay ninguna tarea doméstica que sea realizada mayoritariamente por los hombres y sólo hay tres en las que participan conjuntamente: levantarse por las noches para atender al niño, ayudar a los niños en los deberes y estar con los niños después del colegio.

\section{CUADRO 21}

Tareas según quien las realiza

\begin{tabular}{|c|c|c|c|c|}
\hline Tareas & Mujer & Pareja & Ambos & Ninguno \\
\hline Preparar desayuno ...................... & 49,6 & 8,1 & 38,0 & 4,5 \\
\hline Preparar comida ...................... & 66,5 & 6,7 & 18,4 & 8,3 \\
\hline Fregar/recoger mesa ................ & 55,8 & 6,5 & 30,7 & 7,1 \\
\hline 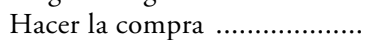 & 49,7 & 6,4 & 42,3 & 1,6 \\
\hline 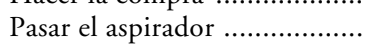 & 60,1 & 5,2 & 23,0 & 11,8 \\
\hline Limpiar los cristales ................ & 65,0 & 5,0 & 16,1 & 14,0 \\
\hline 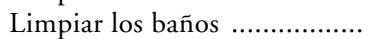 & 69,9 & 1,9 & 15,1 & 13,1 \\
\hline 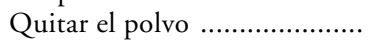 & 62,3 & 2,7 & 20,9 & 14,1 \\
\hline 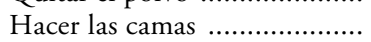 & 60,7 & 4,3 & 28,5 & 6,5 \\
\hline 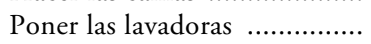 & 77,1 & 3,0 & 14,0 & 5,9 \\
\hline 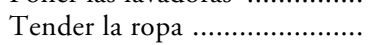 & 68,4 & 5,7 & 18,1 & 7,8 \\
\hline 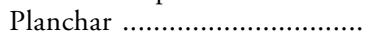 & 76,4 & 2,0 & 9,9 & 11,7 \\
\hline Llevar/traer niños colegio ....... & 30,1 & 8,9 & 24,9 & 36,1 \\
\hline Llevar niños al médico ............ & 48,6 & 4,7 & 39,2 & 7,5 \\
\hline Ayudar en los deberes ............. & 29,5 & 10,2 & 38,3 & 22,1 \\
\hline $\begin{array}{l}\text { Estar con los niños después del } \\
\text { colegio }\end{array}$ & 33,1 & 8,2 & 33,7 & 25,0 \\
\hline $\begin{array}{l}\text { Levantarse noches para atender } \\
\text { niños }\end{array}$ & 40,0 & 5,1 & 46,5 & 8,3 \\
\hline 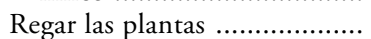 & 54,9 & 11,8 & 17,6 & 15,7 \\
\hline
\end{tabular}

FuENTES: C. Tobío, «Conciliación o contradicción: cómo hacen las madres trabajadoras», REIS, n. ${ }^{\circ}$ 97, pp 155-186; Encuesta de Compatibilización Familia-Empleo, 1998.

${ }^{34}$ Julio Iglesias de Ussel, «Familia», en Fundación FOESSA, V Informe Sociológico sobre la situación social en España, Madrid, 1994, p. 468.

35 J. Iglesias, V Informe FOESSA, 1994.

36 C. Tobío, "Conciliación o contradicción: cómo hacen las madres trabajadoras", REIS, n. ${ }^{\circ}$ 97, 2001, pp. 155-186. 
La mujer se dedica predominantemente a lo que son las tareas de limpiar la casa, poner la lavadora y preparar la comida, es decir, a lo que tradicionalmente ha venido haciendo. Si algunas de las tareas descritas en el cuadro son realizadas por miembros ajenos a la pareja, sus actividades son principalmente las que tienen que ver con los niños, como llevarlos al colegio, ayudarles en los deberes y estar con ellos después del colegio (36, 22, 25\%, respectivamente), así como las relacionadas con las tareas de limpieza y organización de la casa, como limpiar los cristales o quitar el polvo (14\% para ambos).

El análisis de la compatibilización entre el trabajo de la mujer en el mercado laboral y la necesidad de hacer frente a las tareas domésticas se presenta como un problema para las mujeres y, en último caso, para el propio funcionamiento y bienestar de la familia. La rápida extensión de la actividad laboral femenina se acompaña en España de una escasa frecuencia del trabajo a tiempo parcial, de insuficientes servicios para el cuidado de los niños y de una reducida participación del hombre en las tareas domésticas (Tobío, 2002).

\section{La ayuda familiar}

Entre las muchas cuestiones que este asunto plantea se halla la identificación de lo que facilita de alguna manera el poder trabajar y llevar la casa al mismo tiempo. Según se desprende del cuadro 22, sólo el 9,2\% de las mujeres recurren a la ayuda remunerada, y el $7,8 \%$ cree que tal compatibilización se la facilita casi igualmente el horario de trabajo.

El papel masculino adquiere relevancia en este punto, ya que un cuarto de las mujeres cuentan con la ayuda del marido. Sin embargo, lo que interesa es el apoyo que la mujer trabajadora recibe de la red familiar: el 36,9\% de las mujeres lo obtienen de un familiar cercano, pero la contribución no es igual por parte de todos los miembros, porque las grandes protagonistas de la compatibilización entre trabajo y familia son las abuelas maternas, las de la propia entrevistada, en un $27 \%$ de los casos.

De los datos anteriores podemos deducir la importancia de la ayuda familiar y el protagonismo de las abuelas maternas, pero ¿qué pasa con los demás miembros de la familia?, ¿quiénes son? y, sobre todo, ¿qué tipo de ayuda ofrecen o en qué tareas echan una mano? Con los datos del cuadro 23 podemos comprobar la importancia de la abuela materna en la ayuda a la mujer trabajadora, pero existe una gran diferencia entre los abuelos maternos y los abuelos paternos, ya que los primeros ayudan más que los segundos. El $75 \%$ de las abuelas paternas no contribuyen nada, frente al $46,2 \%$ de las abuelas maternas que no ayudan. En el caso de los abuelos son los maternos los que ayudan más, y en cuanto a los demás parientes, aunque no se puede decir que ayuden demasiado, sí podemos apreciar que son los parientes femeninos los que más colaboración prestan. 


\section{CUADRO 22}

\section{Qué ayuda más a las madres trabajadoras a hacer} familia y empleo compatibles

\begin{tabular}{|c|c|}
\hline La ayuda de su madre & 26,7 \\
\hline 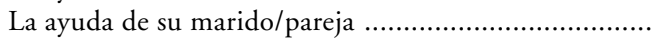 & 24,7 \\
\hline Vivir cerca de su trabajo & 13,9 \\
\hline La ayuda de otros miembros de la familia . & 10,2 \\
\hline La ayuda doméstica remunerada ............... & 9,2 \\
\hline 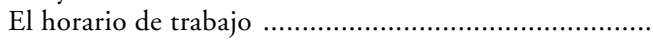 & 7,8 \\
\hline 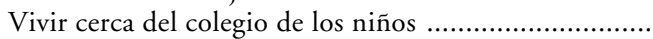 & 4,4 \\
\hline Los servicios que ofrece el centro escolar .......................... & 1,5 \\
\hline Otros recursos & 0,7 \\
\hline Nada & 0,8 \\
\hline
\end{tabular}

Los datos se refieren a todas las madres trabajadoras que viven al menos con un hijo de menos de 18 años.

Fuentes: C. Tobío, «Conciliación o contradicción: cómo hacen las madres trabajadoras", REIS, n. ${ }^{\circ}$ 97, pp. 155-186; Encuesta de Compatibilización FamiliaEmpleo, 1998.

Por lo que hace al tipo de tareas en las que se recibe ayuda no hay diferencias: en tareas de limpieza y trabajos relacionados con el mantenimiento del hogar es mínima, y la principal es la aportación al cuidado de los niños en cuanto a hacerles compañía o llevarlos y traerlos del colegio. En cuanto a preparar la comida para el marido y la mujer, sólo lo asumen las abuelas maternas y no hay diferencia entre hacer la comida para la hija y para el marido o pareja de la entrevistada.

Otras ocasiones de ayuda familiar se presentan los fines de semana o por la noche, cuando salen los padres, y en periodos de vacaciones escolares. La abuela materna vuelve a ser la "salida" mayoritaria ante estas situaciones y otras extraordinarias que se presenten ${ }^{37}$.

La aportación de ayuda familiar es muy valorada por la población femenina trabajadora. El $16,8 \%$ manifiesta que no podría trabajar si no existiera y cerca del $50 \%$ la considera muy o bastante importante. A priori, puede pensarse que esta valoración está influenciada por el nivel socioeconómico de la entrevistada, pero, según los datos del cuadro 24, la diferencia en cuanto a la importancia otorgada no es mucha. Sin embargo, aunque las mujeres de clase socioeconómica más baja no se diferencian en cuanto a la importancia que le

${ }^{37}$ C. Tobío, «Conciliación o contradicción: cómo hacen las madres trabajadoras», REIS, n. ${ }^{\circ}$ 97, 2001, pp 155-186. 


\section{CUADRO 23}

Ayuda que aporta la red familiar de las madres trabajadoras en tareas domésticas ordinarias

\begin{tabular}{|c|c|c|c|c|c|c|}
\hline & $\begin{array}{l}\text { Abuela } \\
\text { materna }\end{array}$ & $\begin{array}{l}\text { Abuelo } \\
\text { materno }\end{array}$ & $\begin{array}{l}\text { Abuela } \\
\text { paterna }\end{array}$ & $\begin{array}{l}\text { Abuelo } \\
\text { paterno }\end{array}$ & $\begin{array}{l}\text { Otros parientes } \\
\text { femeninos }\end{array}$ & $\begin{array}{c}\text { Otros parientes } \\
\text { masculinos }\end{array}$ \\
\hline Cuidar niños en edad preescolar .......................... & 31,3 & 18,8 & 15,0 & 7,4 & 6,6 & 2,2 \\
\hline 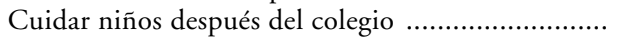 & 38,2 & 15,7 & 17,5 & 8,5 & 8,1 & 2,8 \\
\hline Llevar/traer niños del colegio ................................ & 18,6 & 10,6 & 8,9 & 4,7 & 5,6 & 0,6 \\
\hline Preparar comida para niños .................................. & 23,0 & 4,5 & 6,0 & 1,1 & 3,2 & 0,1 \\
\hline Preparar comida para la entrevistada ................... & 18,3 & 2,2 & 3,1 & 0,0 & 1,9 & 0,0 \\
\hline Preparar comida marido entrevistada .................... & 11,9 & 1,5 & 3,1 & 0,2 & 1,3 & 0,0 \\
\hline 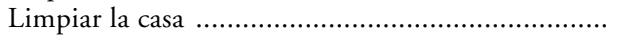 & 9,4 & 0,7 & 1,7 & 0,0 & 3,2 & 0,4 \\
\hline 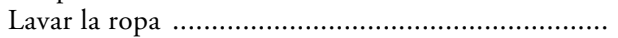 & 8,6 & 0,4 & 1,7 & 0,0 & 2,7 & 0,3 \\
\hline 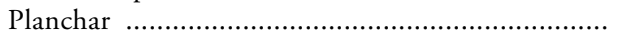 & 8,8 & 0,2 & 2,3 & 0,0 & 1,6 & 0,1 \\
\hline Coser & 8,2 & 0,2 & 1,4 & 0,0 & 2,1 & 0,1 \\
\hline 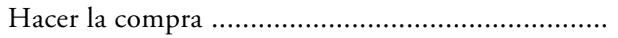 & 8,6 & 0,7 & 2,5 & 0,0 & 1,8 & 0,1 \\
\hline Llevar los niños al médico ..................................... & 8,6 & 1,9 & 3,9 & 0,1 & 1,8 & 0,1 \\
\hline Ninguna tarea & 46,2 & 73,8 & 75,9 & 87,4 & 87,4 & 95,3 \\
\hline
\end{tabular}

Porcentaje de madres trabajadoras con parientes que residen en su misma localidad que son ayudadas por ellos.

FUENTES: C. Tobío, «Conciliación o contradicción: cómo hacen las madres trabajadoras», REIS, n. ${ }^{0}$ 97, pp. 155-186; Encuesta de Compatibilización Familia-Empleo, 1998. 
atribuyen, la falta de ayuda supone para ellas el no poder trabajar y eso es, al parecer, lo que más les importa.

Una última cuestión que nos queda por analizar es cuál es la ayuda remunerada a la que las mujeres trabajadoras recurren. Un $27,6 \%$ de las mujeres la obtienen y, a medida que el nivel socioeconómico es más elevado, el porcentaje de mujeres que la utilizan es mayor ${ }^{38}$.

CUADRO 24

Opinión acerca de la importancia de la ayuda familiar por nivel socioeconómico de la entrevistada

\begin{tabular}{|c|c|c|c|c|}
\hline & Alto & Medio & Bajo & $T$ \\
\hline Sin ayuda no podría trabajar. & 10,8 & 13,4 & 24,2 & 16,8 \\
\hline 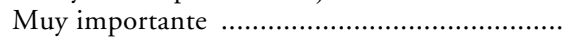 & 32,5 & 29,7 & 19,7 & 26,5 \\
\hline Importante o bastante importante ...................... & 18,1 & 20,5 & 21,7 & 20,4 \\
\hline 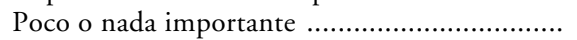 & 38,6 & 36,4 & 34,4 & 36,2 \\
\hline
\end{tabular}

Base: entrevistadas con red familiar en su localidad.

FuENTES: C. Tobío, «Conciliación o contradicción: cómo hacen las madres trabajadoras», REIS, n. 97, pp. 155-186; Encuesta de Compatibilización Familia-Empleo, 1998.

\section{Relaciones afectivas y de conflictividad}

Los datos disponibles sobre los matrimonios españoles revelan que dentro de ellos la armonía conyugal, sin ser perfecta ni carecer de problemas, es aceptable. En este sentido, la válvula de escape que supone el divorcio, abierta legalmente en 1981, no parece haber resuelto ni sacado a la superficie demasiados conflictos soterrados. En cualquier caso, éste ha sido uno de los cambios más importantes acaecidos en la familia española en la última década y, presumiblemente, ha servido para frenar el desarrollo de algunas fórmulas alternativas al matrimonio y a la familia.

Entre los indicadores que se utilizan para analizar la armonía conyugal contamos con algunos procedentes de encuestas sobre la interacción matrimonial —el reparto de actividades, problemas y actitudes - y la satisfacción ${ }^{39}$. En general, la inmensa mayoría de los matrimonios realizan conjuntamente las actividades de ocio más frecuentes: ir al cine o al teatro, salir a comer a un restaurante y a casa de amigos y parientes, pasear, etc. La pareja comparte tam-

${ }^{38}$ C. Tobío, «Conciliación o contradicción: cómo hacen las madres trabajadoras", REIS, n. ${ }^{\circ}$ 97, 2001, pp 155-186.

39 Ibidem, pp 150-156. 
bién con mucha frecuencia los problemas personales, de trabajo, económicos y otros, de los hijos y de los parientes, y su grado de satisfacción con la vida familiar y el matrimonio es alto, tal y como se puede deducir de los datos del cuadro 25 .

\section{CUADRO 25}

Satisfacción con aspectos del matrimonio

\begin{tabular}{|c|c|}
\hline Aspectos del matrimonio & $\begin{array}{l}\text { Muy o bastante } \\
\text { satisfecho (\%) }\end{array}$ \\
\hline El afecto hacia el cónyuge .............. & 99 \\
\hline 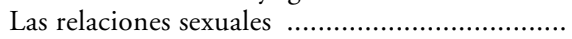 & 77 \\
\hline El nivel de vida económico ................................ & 69 \\
\hline 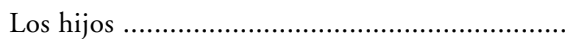 & 87 \\
\hline La personalidad del cónyuge ............................... & 77 \\
\hline
\end{tabular}

Otro de los indicadores que permite valorar la satisfacción con el funcionamiento de las relaciones de pareja refleja la percepción de lo que da y lo que recibe cada uno de los miembros de la pareja. En general, más mujeres que hombres declaran dar más que recibir y son más los hombres que declaran dar menos de lo que reciben. El porcentaje de la aportación de ambos es considerable en casi todos los casos (37\% en la aportación económica, $71 \%$ en prestigio social, $71 \%$ en conocimientos, $74 \%$ en sexo y $54 \%$ en cariño y afecto). Los altos porcentajes en conocimientos se deben al grado de igualdad con el hombre que la mujer está adquiriendo, que se revela en la procedencia compartida del prestigio social, que hasta hace poco tiempo era monopolio del hombre. En cuanto el sexo, la liberalización de las relaciones sexuales coloca en una situación similar a hombres y a mujeres.

Las aportaciones menos igualitarias se refieren a tres aspectos que en gran medida perpetúan los roles de hombres y mujeres. Por un lado, las mujeres reconocen ser más afectivas y dar más cariño que los hombres; por otro, los dos aspectos que se mantienen de forma clara se refieren a los recursos económicos y a las tareas del hogar. Aunque sea una realidad su incorporación al mercado de trabajo y aporten sus ingresos al hogar, el 64\% de las mujeres afirman que los recursos económicos los aporta el marido. El trabajo doméstico sigue siendo monopolio de la mujer, sólo el $4 \%$ de las mujeres afirman que los hombres contribuyen a las tareas del hogar ${ }^{40}$. Pese a estas diferencias, sin embargo, la satisfacción de la población española con el funcionamiento de la

${ }^{40}$ Actitudes y conductas interpersonales de los españoles ante el plano afectivo, Estudio 2157, CIS, 1995. Elaboración propia. 
relación de pareja es bastante considerable: el 91\% está muy o bastante satisfecho, según la encuesta del CIS sobre las relaciones interpersonales realizada en 1995.

Entre los indicadores relativos a la conflictividad disponemos de datos referentes a las discusiones, que sólo afectan a un porcentaje relativamente alto (del 33 al 44\%) si versan sobre las relaciones con parientes, la educación de los hijos y cuestiones de dinero. Aun así, la mayoría no discute casi nunca, ni siquiera sobre estos temas, aunque no debemos olvidar que a veces la ausencia de debates encubre una conflictividad latente en la cual se ha cortado totalmente el diálogo.

El cuadro 26 recoge los resultados de una batería de preguntas diseñadas para ahondar en la experiencia de las crisis matrimoniales, su disolución y sus consecuencias, junto con un índice de conflictividad ${ }^{41}$. Los datos muestran claramente que la conflictividad conyugal no es un fenómeno extraño a la vida familiar, pero que pocas veces llega a ser tan grave como para desencadenar un divorcio. Los datos extremos son muy elocuentes: el $66 \%$ de las mujeres entrevistadas declara haber pasado crisis en su matrimonio, con consecuencias, en algunos casos, de insultos, abandono del hogar y hasta de malos tratos físicos, en tanto que sólo el $2 \%$ considera su crisis insuperable. La distancia entre ambos porcentajes es, posiblemente, la que lleva a que el recurso a la disolución matrimonial sea mínimo, tal y como revelan los datos disponibles sobre divorcialidad $^{42}$.

${ }^{41}$ El índice se corresponde con la respuesta que se da a la pregunta "¿Diría usted que en la actualidad su matrimonio marcha bien o tiene problemas?». En el caso de tener problemas se les preguntó si consideraban que la crisis era superable o no. A estas tres preguntas se les atribuyen los valores bajo, medio y alto del índice.

${ }^{42}$ Cfr. Santiago Borrajo Iniesta, La ruptura matrimonial en España, Eudema, Madrid, 1990. Por otro lado, según la Memoria del Tribunal Superior de Justicia de Madrid, los asuntos tramitados por los Juzgados de Familia disminuyeron en un 15,7\% en 1989 respecto al año anterior (Otrosi Informativo, 39, junio 1990, pp. 14-15). 


\section{CUADRO 26}

Entrevistados que declaran haber pasado crisis en su matrimonio, consecuencias e indice de conflictividad por edad, 1980

\begin{tabular}{|c|c|c|c|c|c|}
\hline & \multirow[b]{2}{*}{ Total } & \multicolumn{4}{|c|}{ Edad } \\
\hline & & $18-29$ & $30-44$ & $45-59$ & 60 y más \\
\hline \multicolumn{6}{|l|}{ Veces que han pasado crisis } \\
\hline Muchas o bastantes ................... & 34 & 32 & 35 & 34 & 32 \\
\hline 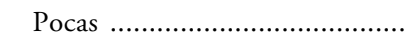 & 32 & 28 & 31 & 34 & 32 \\
\hline 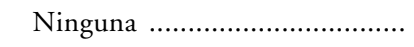 & 28 & 33 & 27 & 26 & 27 \\
\hline \multicolumn{6}{|l|}{ Consecuencias } \\
\hline No hablarse durante días .......... & 28 & 26 & 31 & 29 & 21 \\
\hline Abandono del hogar una noche & & & & & \\
\hline 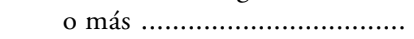 & 4 & 2 & 5 & 4 & 3 \\
\hline 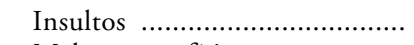 & 11 & 14 & 12 & 8 & 8 \\
\hline 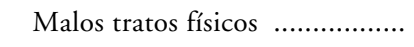 & 2 & 3 & 2 & 2 & 2 \\
\hline \multicolumn{6}{|l|}{ Indice de conflictividad } \\
\hline 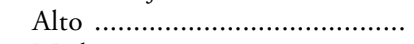 & 2 & 2 & 2 & 2 & 1 \\
\hline 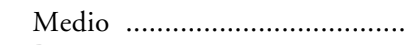 & 4 & 8 & 5 & 3 & 1 \\
\hline 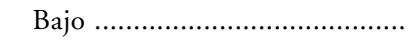 & 94 & 90 & 93 & 95 & 98 \\
\hline
\end{tabular}

FUENTE: Encuesta inédita sobre la familia española, dirigida por S. del Campo, 1980.

\section{Separaciones y divorcios}

Las tasas de separaciones y divorcios se presentan en el cuadro 27 , del que se desprende que, una vez aprobada la Ley de 1981, hubo una línea ascendente de separaciones y de divorcios hasta 1990, en torno a 14-18 para las separaciones y a 10 para los divorcios, habiendo registrado desde entonces, tanto las separaciones como los divorcios, un crecimiento estable.

Respecto a las causas o motivos de la separación y del divorcio hay que distinguir entre las reales, manifestadas por los propios afectados, y las legales, que se ajustan a una clasificación tipificada. Estos dos tipos de causas no tienen por qué coincidir. En el cuadro 28 se presentan las causas reales y legales recogidas por Doménech en una investigación realizada en Valencia en el año 1994 y citadas por Ruiz Becerril en su obra sobre las consecuencias del divorcio. Entre las causas reales, la falta de y la mala comunicación, la incompatibilidad de caracteres, la infidelidad del marido y los abusos psíquicos ocupan los primeros lugares. En cuanto a las causas legales, la incompatibilidad de caracteres y el mutuo acuerdo son las dos más frecuentes, sin que se observe concordancia entre los dos tipos de causas. 


\section{CUADRO 27}

Tasas de separaciones y divorcios, 1982-2000*

\begin{tabular}{|c|c|c|c|c|c|}
\hline \multirow[b]{2}{*}{ Años } & \multicolumn{2}{|c|}{ Separaciones } & \multicolumn{2}{|c|}{ Divorcios } & \multirow[b]{2}{*}{ Total S/D } \\
\hline & Absolutos & Porcentajes & Absolutos & Porcentajes & \\
\hline $1982 \ldots \ldots \ldots . . .$. & 17.445 & 9,02 & 21.463 & 11,10 & 38.908 \\
\hline $1983 \ldots \ldots \ldots . . . .$. & 19.651 & 10,02 & 19.306 & 9,84 & 38.957 \\
\hline 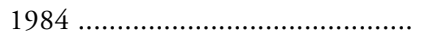 & 22.224 & 11,25 & 17.656 & 8,94 & 39.880 \\
\hline 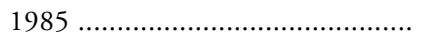 & 25.046 & 12,54 & 18.291 & 9,16 & 43.337 \\
\hline 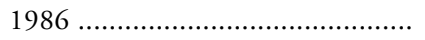 & 27.553 & 13,25 & 19.234 & 9,25 & 46.787 \\
\hline $1987 \ldots \ldots . . .$. & 31.153 & 14,44 & 21.326 & 9,88 & 52.479 \\
\hline 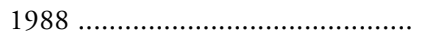 & 33.240 & 15,18 & 22.449 & 10,25 & 55.689 \\
\hline $1989 \ldots \ldots \ldots . . .$. & 34.672 & 15,65 & 23.063 & 10,41 & 57.735 \\
\hline 1990 . & 36.272 & 16,45 & 23.191 & 10,51 & 59.463 \\
\hline 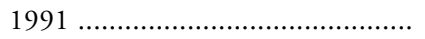 & 39.758 & 18,23 & 27.224 & 12,48 & 66.982 \\
\hline 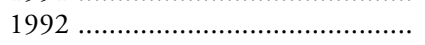 & 39.918 & 18,35 & 26.783 & 12,31 & 66.701 \\
\hline 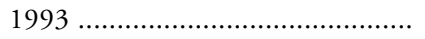 & 43.491 & 21,59 & 28.854 & 14,32 & 72.345 \\
\hline 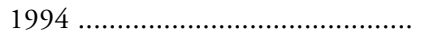 & 47.546 & 23,80 & 31.522 & 15,78 & 79.068 \\
\hline 1995 & 49.374 & 24,60 & 33.104 & 16,49 & 82.478 \\
\hline 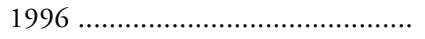 & 51.317 & 26,90 & 32.571 & 17,07 & 83.888 \\
\hline 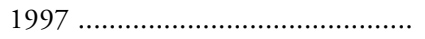 & 54.728 & 27,85 & 34.147 & 17,37 & 88.875 \\
\hline 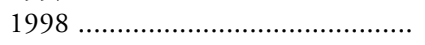 & 56.837 & 28,92 & 36.072 & 18,35 & 92.909 \\
\hline 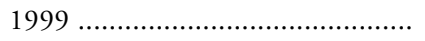 & 59.547 & 30,02 & 36.900 & 18,77 & 96.447 \\
\hline 2000 & 63.430 & 32,28 & 39.973 & 20,03 & 103.403 \\
\hline
\end{tabular}

* Por 100 matrimonios.

FuENTES: Ruiz Becerril, Después del divorcio. Los efectos de la ruptura matrimonial, CIS, Madrid, 1999. Los datos absolutos, Memoria del Consejo Superior del Poder Judicial, años correspondientes. Años 1997-2000, Consejo Superior del Poder Judicial y Movimiento Natural de la Población, 1997-2000.

Según las Estadísticas Judiciales de nuestro país, las principales causas de las separaciones son el mutuo acuerdo y las provocadas por infidelidad conyugal, abandono del hogar y conducta vejatoria. Respecto a las causas de divorcio, la mayoría de los procesos se hacen efectivos cuando se produce un cese de la convivencia ininterrumpidamente desde la presentación de la demanda de separación, haya o no mutuo acuerdo. Una última clasificación aportada por estas estadísticas son las causas de nulidad, entre las que se encuentran las declaradas por el Tribunal eclesiástico, y los actos realizados sin consentimiento matrimonial o algún error de identidad ${ }^{43}$.

La disolución del núcleo familiar tiene grandes y diferentes tipos de consecuencias para los miembros de la familia ${ }^{44}$. Tradicionalmente, las consecuencias

${ }^{43}$ Estadisticas Judiciales, 1995 y 1999, INE; Código Civil, Tecnos, 1995.

${ }^{44}$ D. Ruiz Becerril, Después del divorcio. Los efectos del divorcio, Monografía 169, CIS, 1999. 


\section{CUADRO 28}

Causas reales y legales de la ruptura

\begin{tabular}{|c|c|c|c|}
\hline Reales & & Legales & \\
\hline Problemas de comunicación ..................... & 63 & Incompatibilidad de caracteres. & 33 \\
\hline Incompatibilidad de caracteres ................... & 61 & Mutuo acuerdo ......................... & 30 \\
\hline Infidelidad del marido ................ & 45 & Abuso físico .... & 8 \\
\hline 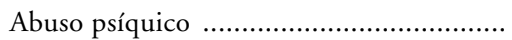 & 34 & 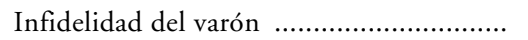 & 8 \\
\hline Problemas sexuales ..................................... & 25 & Liberalización de la mujer ......................... & 8 \\
\hline Problemas económicos ............................... & 22 & 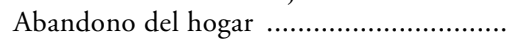 & 3 \\
\hline 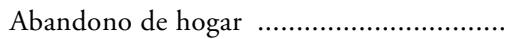 & 18 & Problemas de comunicación ....................... & 2 \\
\hline Liberalización de la mujer ......................... & 18 & 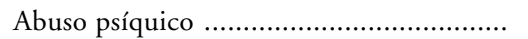 & 2 \\
\hline Problemas con familia política ................. & 13 & 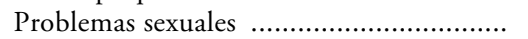 & 2 \\
\hline 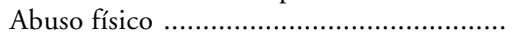 & 13 & Por los hijos ........... & 2 \\
\hline Alcoholismo del marido ............................. & 8 & NC & 5 \\
\hline Enfermedad mental .................................... & 8 & & \\
\hline Problemas por los hijos ............................... & 7 & & \\
\hline Infidelidad de la mujer .............................. & 7 & & \\
\hline Distintas creencias religiosas $\ldots \ldots \ldots \ldots \ldots \ldots \ldots$ & 1 & & \\
\hline Alcoholismo de la mujer ........................ & 1 & & \\
\hline
\end{tabular}

FuENTE: D. Ruiz Becerril, Después del divorcio. Efectos de la ruptura matrimonial, CIS, 1999.

económicas tienen como principal protagonista a las mujeres y, por otro lado, están los hijos, que sufren por una decisión ajena a su propia voluntad. Respecto al factor económico, que es un rasgo patente y directo de la ruptura, cabe afirmar que determina significativamente el resto de los procesos ligados al postdivorcio. Lo que sí está claro es que, junto con los efectos que tiene en el grupo familiar al duplicar los gastos por unos mismos servicios, los principales efectos económicos de las rupturas matrimoniales se concentran en las familias monoparentales. Diego Ruiz Becerril considera concretamente los siguientes cuatro:

1. La feminización de la pobreza. La ruptura matrimonial tiene un desenlace económico diferente para el varón y para la mujer. Los resultados de diversos estudios confirman que el varón, como media, mantiene un nivel de vida parecido al que disfrutaba antes de la separación, o que incluso la separación provoca un ascenso de su nivel de vida. Por el contrario, la situación de la mujer es distinta: sufre un empobrecimiento evidente en relación con el nivel de vida que disfrutaba anteriormente y que se agrava por tener a su cargo los hijos, lo cual incide en el nivel de vida de los propios hijos de los divorciados, hasta tal punto que no sólo nos encontramos ante la feminización de la pobreza, sino también ante la infantilización de la pobreza.

En España se dispone de una cuantificación de las madres cabezas de fami- 
lia que viven por debajo de la mitad de los ingresos medios de los hogares y se comprueba que es uno de lo países con menores tasas de empobrecimiento $(9,2 \%)$, junto con Bélgica $(7,8 \%)$ o Italia.

2. Pago de pensiones. El pago de las pensiones es la dimensión económica que origina un mayor número de problemas en los procesos postdivorcio. En nuestro régimen legal español existen dos tipos de pensiones, las alimenticias y las compensatorias. Las primeras se deben a los hijos y, en cuanto a las compensatorias, éstas son concedidas cuando se ocasionan desequilibrios económicos significativos entre los cónyuges durante el matrimonio y las solicita el cónyuge que queda en situación de desventaja.

Según un informe de 1989 del Consejo General del Poder Judicial, la percepción social de impago de pensiones no se corresponde con la realidad. El incumplimiento total de sentencias se restringe al $14 \%$, lo que lo convierte en un fenómeno minoritario. Hay que tener en cuenta que la mayoría de las sentencias cede la custodia a la madre y obliga al padre al pago de pensiones. Las pensiones alimenticias, que son en mayor medida las que no se pagan, en la mitad de los casos no exceden de los 300 euros, lo que explica que son precisamente las familias que más ayuda o pensión necesitan las que en mayor grado sufren el incumplimiento que agrava su situación de pobreza.

Las circunstancias de la madre y de los hijos no se relacionan ni con que se paguen las pensiones ni con las cuantías. Existen otros condicionantes, como el estatus socioeconómico de la familia, las segundas nupcias, la distancia física de los cónyuges, la edad de los hijos, etc. Otro aspecto importante a considerar es la relación positiva directa entre el pago de pensiones y las visitas.

3. Actividad ocupacional y ruptura matrimonial. Entre las estrategias para afrontar los efectos económicos de la ruptura adquieren especial importancia la búsqueda de trabajo doméstico o aumentar las horas de trabajo si ya lo practica. Se trata de una actitud adoptada por la mujer, que es quien tradicionalmente trabajaba menos fuera del hogar. En España, el 60\% de las mujeres separadas y divorciadas prefieren depender de ellas mismas económicamente y no tener problemas con las pensiones.

En España, las mujeres divorciadas y separadas trabajan más que la media de la población femenina, mientras que el porcentaje de los varones no experimenta ninguna alteración. La actividad se considera como una salida a los problemas económicos que la ruptura plantea, por lo que la existencia de la actividad laboral de la mujer puede ser tanto una causa de ella como una consecuencia. Lo cual no significa que la mujer trabaje sólo cuando se divorcia, y así lo prueba que el $86 \%$ de las separadas y divorciadas tuvieron su primer trabajo con anterioridad a la ruptura y el $9 \%$ recurrió al mercado laboral cuando empezaron los trámites de separación. Lo que sí está claro es que la mujer casada que trabaja ve las cosas de otra manera y tiene más cerca o más fácil la posibilidad de divorcio que la mujer casada que no trabaja. 
4. El apoyo de las redes sociales. La ruptura matrimonial no supone sólo la disolución de una familia, sino que en muchas ocasiones provoca la pérdida de la red social que se ha consolidado con el matrimonio. Después de un divorcio o de una separación, la red social se resiente a causa del papel que juega en el apoyo requerido por los propios divorciados y separados. La mayoría de las ayudas y de los apoyos proceden de la familia y, dentro de ésta, de miembros como los padres y los hermanos, esto aparte de que también los amigos de la pareja constituyen otro grupo de apoyo.

Respecto a los efectos del divorcio en los hijos, el discurso tradicional insiste en la defensa del modelo de familia nuclear como óptimo para el desarrollo emocional del individuo. La familia como agente de socialización integra al individuo en la sociedad y le transmite un complejo legado de actitudes y comportamientos. El problema principal consiste en la manera como la ruptura de los padres repercute en general en el estado anímico de los hijos, y particularmente en su rendimiento escolar, dado que la mayoría de los hijos afectados desarrollan sus actividades en ese ámbito. En España, Pons (1997) concluye que, aunque los hijos de familias separadas tienen peor rendimiento escolar que los de familias intactas, no se puede considerar que estas diferencias sean significativas. El cuadro 29 muestra el nivel educativo del hijo según el estado civil de los padres, y en él se comprueba que las diferencias en este aspecto entre hijos de familias rotas y de familias intactas empiezan a notarse en los niveles educativos más altos.

\section{CUADRO 29}

Nivel educativo del hijo según estado civil de los padres

\begin{tabular}{|c|c|c|}
\hline & Matrimonio intacto & Matrimonio roto \\
\hline Sin estudios & 1,4 & 1,9 \\
\hline 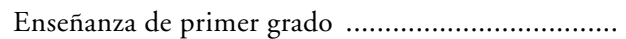 & 45,9 & 50,3 \\
\hline \multicolumn{3}{|l|}{ Enseñanza de segundo grado: } \\
\hline 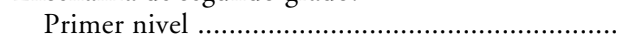 & 3,7 & 2,8 \\
\hline Segundo nivel & 15,4 & 18,2 \\
\hline 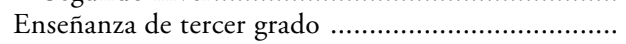 & 33,6 & 26,8 \\
\hline TOTAL & 100 & 100 \\
\hline
\end{tabular}

Fuente: D. Ruiz Becerril, Después del divorcio. Efectos de la ruptura matrimonial, CIS, 1999.

Respecto a los factores que pueden afianzar estas diferencias podemos considerar que la edad de los hijos no es determinante, aunque es verdad que en los hijos más jóvenes de padres separados existen menos problemas, debido principalmente al tiempo transcurrido desde la separación; que el sexo del hijo 
no influye significativamente en la relación entre el estado civil de los padres y el nivel educativo de los hijos; y que el estatus socioeconómico, más el aspecto económico que el nivel educativo de los padres, tiene una gran influencia.

Algunos autores han llamado la atención sobre la posibilidad de que el incremento de la ruptura matrimonial puede deberse a la transmisión intergeneracional de la inestabilidad en el matrimonio, por lo que los hijos de familias separadas tienen más probabilidad de ruptura e inestabilidad matrimonial que los de familias intactas. Diversas investigaciones han mostrado que los hijos de familias separadas son más propensos a cohabitar y a adelantar las relaciones sexuales y, en cuanto a la hipótesis planteada, la transmisión del comportamiento por parte de los padres sobre los hijos existe y se traduce, entre otros rasgos, por una edad más temprana al casarse, menor nivel educativo y mayor riesgo de embarazo prenupcial.

Después de una ruptura matrimonial, por otro lado, la probabilidad de empezar una nueva relación y las pretensiones de ésta son diferentes si se trata de un hombre o de una mujer. En general, el 75,3\% de los divorciados/as no mantienen ninguna relación, el $11 \%$ ha vuelto a contraer matrimonio y cerca del $14 \%$ cohabita. Los varones tienen más facilidad para empezar una nueva relación y consolidarla en el matrimonio, o para cohabitar, que es para ellos una salida más probable que casarse (cuadro 30).

\section{CUADRO 30}

Situación de los divorciados tras la ruptura

\begin{tabular}{|c|c|c|c|}
\hline & Varón & Mujer & Total \\
\hline 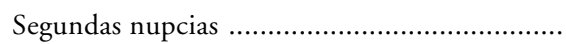 & 16,4 & 7,3 & 11,0 \\
\hline Cohabitación postmatrimonial $\ldots \ldots \ldots \ldots \ldots \ldots \ldots \ldots$ & 17,8 & 10,9 & 13,7 \\
\hline Sin ninguna nueva unión & 65,8 & 81,8 & 75,3 \\
\hline TOTAL & 100 & 100 & 100 \\
\hline
\end{tabular}

Fuentes: D. Ruiz Becerril, Después del divorcio. Efectos de la ruptura matrimonial, CIS, 1999; Encuesta Sociodemográfica, 1991, INE.

\section{Relaciones paterno-filiales}

Las relaciones entre padres e hijos, especialmente cuando éstos son adolescentes o jóvenes, integran otro capítulo en el que la familia española también ha cambiado notablemente. De ser muy conflictivas en los años sesenta y setenta pasaron en los ochenta a caracterizarse por un relativo mejor entendimiento. La democratización interna de la familia, la mejora de la educación de 
los padres, la mayor permisividad social, ética y familiar, y los propios valores asumidos por la juventud actual, muy castigada por su marginación real, contribuyen a respaldar este significativo cambio. El resultado es que, a diferencia de la juventud anterior, que buscaba salir del hogar cuanto antes, la de ahora se instala confortablemente en él y no tiene prisa por abandonarlo. Según datos del Instituto Nacional de Juventud, la proporción de jóvenes que viven en el hogar familiar es bastante considerable. En el año 2000, el 77\% de los jóvenes españoles no se habían independizado ${ }^{45}$.

La situación social que actualmente viven los jóvenes españoles está determinada por la situación de paro a la que se enfrentan, los precios de las viviendas y la formación continua requerida por un mercado laboral cada vez más competitivo y en el que hay que entrar siempre mejor preparado. Esto trae como consecuencia para los hijos una dependencia económica de los padres, que se ve reflejada en el cuadro 31 y que no ha cambiado desde mediados de los años ochenta. Un tercio de los jóvenes españoles viven de sus ingresos, y la mitad sin ningún tipo de ayuda. Por el contrario, la mitad de los jóvenes dependen en su totalidad de los recursos familiares y el 19\% lo considera su ingreso principal.

\section{CUADRO 31}

\section{Origen de los recursos económicos}

\begin{tabular}{lcc}
\hline & 1984 & 1996 \\
\cline { 2 - 3 } & 52 & 49 \\
Viven exclusivamente de los recursos familiares ...... & 23 & 19 \\
Viven principalmente de los recursos familiares ..... & 11 & 16 \\
Viven principalmente de los ingresos propios ........ & 14 & 16 \\
Viven exclusivamente de los ingresos propios ........ & 14 \\
\hline
\end{tabular}

FUENTE: Informe de la Juventud, 1984, 1996, INJUVE.

La coexistencia de dos generaciones socializadas en dos Españas diferentes y la prolongación de la permanencia de los jóvenes en el hogar familiar pueden provocar ciertas tensiones familiares, que no están exentas de problemas pero que, en general, son bastante soportables. El nivel de comunicación y de consenso entre las dos generaciones es bastante aceptable. Los datos que arrojan las investigaciones centradas en la situación de los jóvenes revelan que existe comunicación con los padres y que es fluida (cuadro 32). Cuestiones como los asuntos familiares (77\%) o el ocio (59\%) se comentan frecuentemente en casa. Los temas de los que menos se habla son los relacionados con la sexualidad $(21 \%)$, la política $(26 \%)$, la religión $(26 \%)$ y las drogas $(36 \%)$.

45 Informe de la Juventud, INJUVE, 2000. 


\section{CUADRO 32}

Comunicación (porcentaje con mucha o bastante frecuencia)

\begin{tabular}{|c|c|c|c|}
\hline & \multirow[b]{2}{*}{ Total } & \multicolumn{2}{|c|}{ Género } \\
\hline & & Hombre & Mujer \\
\hline 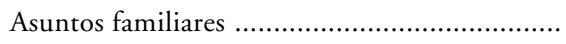 & 77 & 74 & 79 \\
\hline 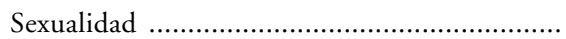 & 21 & 18 & 24 \\
\hline 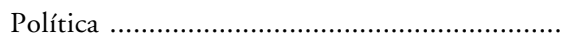 & 26 & 27 & 25 \\
\hline 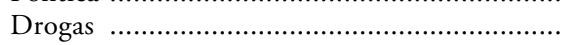 & 36 & 33 & 40 \\
\hline 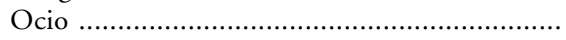 & 59 & 53 & 59 \\
\hline 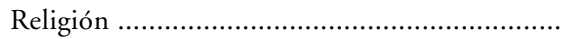 & 26 & 23 & 30 \\
\hline
\end{tabular}

FUENTE: Elaboración propia. Estudio 2262, CIS, 1997.

Pero una cosa es que los temas se traten y otra que exista afinidad o consenso con las ideas de los padres. El grado de acuerdo es bastante alto en todos los temas tratados, si bien se observa menor consenso en las cuestiones políticas y en la sexualidad. Las mujeres, a su vez, comparten más que los hombres con los padres las actitudes hacia las drogas, el ocio y la religión (cuadro 33).

\section{CUADRO 33}

Consenso en las ideas (porcentaje casi siempre o alguna vez)

\begin{tabular}{|c|c|c|c|}
\hline & \multirow[b]{2}{*}{ Total } & \multicolumn{2}{|c|}{ Género } \\
\hline & & Hombre & Mujer \\
\hline 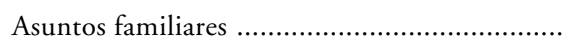 & 87 & 88 & 87 \\
\hline 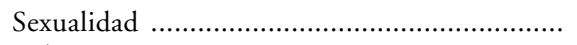 & 61 & 61 & 61 \\
\hline 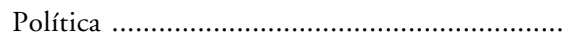 & 68 & 62 & 63 \\
\hline Drogas & 78 & 75 & 80 \\
\hline 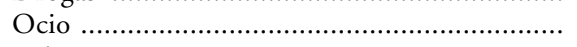 & 77 & 75 & 79 \\
\hline 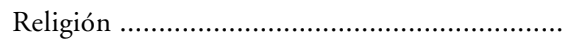 & 69 & 65 & 72 \\
\hline
\end{tabular}

FUENTE: Elaboración propia. Estudio 2262, CIS, 1997.

La diferencia aludida entre generaciones parece no percibirse por los jóvenes, que no consideran a sus padres como estrictos, lo cual puede deberse a que están convencidos de no recibir de ellos una educación autoritaria. Si observamos el siguiente cuadro, hay ciertas actividades que siempre han estado permitidas en el hogar español, como levantarse a la hora que se quiere y reu- 
nirse en casa con amigos. Sin embargo, hay otras actividades respecto a las cuales se advierte cada vez más libertad, y se refieren sobre todo a llegar a la hora que se quiera por la noche, a estar en la casa con el novio/a y a pasar la noche fuera de casa.

Otro indicador que facilita las relaciones entre padres e hijos es el que revela que la mitad de las decisiones que se toman en casa se toman conjuntamente por padres e hijos ${ }^{46}$.

\section{CUADRO 34}

Libertad para hacer ciertas actividades (porcentaje de poder hacerlo)

\begin{tabular}{|c|c|c|c|}
\hline & 1984 & 1988 & 1997 \\
\hline Levantarte cuando quieras ................................... & 60 & 57 & 62 \\
\hline 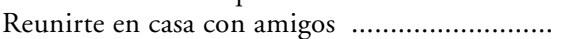 & 81 & 83 & 84 \\
\hline Llegar por la noche a la hora que quieras ......... & 39 & 44 & 59 \\
\hline 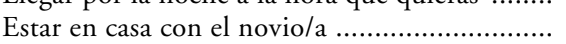 & 66 & 72 & 70 \\
\hline Pasar la noche fuera de casa & 36 & 37 & 61 \\
\hline 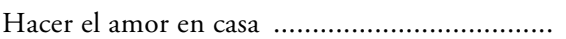 & 8 & 8 & - \\
\hline
\end{tabular}

FUENTES: 1984 y 1988, Informe de la Juventud, 1984, 1988, INJUVE. Dato 1997, elaboración propia, Estudio 2262, CIS, 1997.

\section{LA POLÍTICA FAMILIAR}

El estudio de la política familiar en la segunda mitad del siglo XX puede hacerse desde dos vertientes relacionadas, a partir de un mismo punto de partida: los cambios modernizadores a los que hemos asistido en la familia española. Ellos nos llevan, por una parte, a analizar la legislación que ha facilitado su efectividad y, por otra, a comentar el papel de la institución familiar en el sistema de protección social de nuestro país.

En cuanto al cambio legal, el proceso seguido ha estado marcado por la distinta consideración política, social y económica de la institución familiar en dos regímenes muy diferentes. En el periodo franquista, la familia se definía como la célula primaria de la sociedad y era protegida por los poderes públicos como institución natural a la que había que mantener como tal. Todas las leyes se orientaban a la defensa de la familia tradicional, en la que la mujer era relegada a un segundo plano y puesta bajo la tutoría del marido y en la que las relaciones prematrimoniales y la interrupción voluntaria del embarazo estaban totalmente prohibidas social y legalmente.

Con la llegada de la democracia, la nueva concepción política de la familia

46 Juventud y entorno familiar, Estudio 2262, CIS, 1997. Elaboración propia. 
se recoge en la Constitución de 1978, cuyo artículo 32 afirma que «el hombre y la mujer tienen derecho a contraer matrimonio con plena igualdad jurídica». Este artículo, junto con el 39, que garantiza la protección económica, social y jurídica de la familia, incitaron grandes cambios en nuestra legislación, como el fin del estatus privilegiado del varón sobre la mujer, a pesar de no establecer un marco completo legal de los diferentes aspectos del funcionamiento y formación de la familia.

La legislación requerida para hacer efectivos esos cambios fue promulgándose gradualmente a través de reformas y nuevas leyes que afectaron a diferentes aspectos de la familia, tanto en lo civil como en lo penal y en otros aspectos.

\section{REFORMAS DE LA LEGISLACIÓN CIVIL}

\section{Formas de matrimonio, edad al casarse y divorcio}

Durante el franquismo la única forma reconocida legalmente de matrimonio era la religiosa o canónica, y éste adquiría efecto una vez que el Estado lo inscribía en el Registro Civil. Sólo se permitía el matrimonio civil cuando se probaba que ninguno de los contrayentes profesaba la religión católica. Con la Constitución, el matrimonio civil adquiere la condición legal de que había gozado hasta entonces el matrimonio canónico. A partir de ese momento, la proporción de matrimonios civiles respecto a los religiosos empezó a aumentar: desde el 2,9 de 1979, al 20,6 en 1992 y al 24\% actual, dentro de una baja general de la nupcialidad. La edad de contraer matrimonio quedó fijada en la edad núbil, a pesar de lo cual se ha venido retrasando de manera continuada en las últimas décadas y ha pasado de ser 26,68 años en 1975 para los varones a ser 30,18 en 1999 , y para las mujeres de ser 24,17 a 28,12 en las mismas fechas.

La llamada Ley del Divorcio de 1981 autorizó la disolución voluntaria del matrimonio, especificando el procedimiento a seguir en los casos de nulidad, separación y divorcio. Para ello se fundaron los Juzgados de Familia, evolucionando las tasas de divorcio hasta su estabilización actual. En el momento presente siguen sometidos a debate la regularización de las uniones de hecho y otros asuntos más problemáticos que plantean colectivos de izquierda de nuestra sociedad.

\section{Igualdad entre los hijos y derechos y deberes de los padres}

El reconocimiento de la obligación de los padres de velar por el bienestar de sus hijos, cualquiera que sea la relación jurídica que los vincule con ellos en el momento de la concepción y del nacimiento, sustituye a la vieja distinción de los hijos en legítimos e ilegítimos por la de nacidos dentro y fuera del 
matrimonio. El número de nacimientos fuera del matrimonio ha pasado de ser el 3,9\% en 1980 a ser el $19,6 \%$ en 2000 , aunque también hay que considerar que ha aumentado el porcentaje de los embarazos no deseados.

A partir de 1981, la patria potestad es compartida por ambos progenitores, que toman conjuntamente las decisiones que atañen a sus hijos. Los padres pueden castigar a los hijos y éstos tienen ciertas obligaciones hacia sus padres, a los que deben obedecer, teniendo además la obligación de contribuir a las necesidades de la familia sin ser explotados económicamente. Actualmente los hijos tienen más derechos frente a sus padres. Al alcanzar la mayoría de edad pueden anular cualquier decisión que hayan tomado sus padres durante su minoría y, en casos de separación, a partir de los 12 años cumplidos, la declaración del niño será clave para la decisión que tome el juez.

\section{Adopción}

La regulación de la adopción en nuestro país se ha efectuado varias veces y la última, de 1987, ha terminado con la antigua distinción entre adopción simple y plena, conservando sólo esta última. Se ha fijado la edad mínima para adoptar en 25 años y la diferencia de edad entre los padres adoptivos y el menor en por lo menos catorce años. Con la nueva Ley se extinguen todos los vínculos legales entre el menor y su familia biológica.

\section{Mayoría de edad}

La Constitución rebajó la mayoría de edad de los 21 años a los 18. Este descenso, que suponía la libertad del joven para tomar antes la decisión de emanciparse del hogar familiar, no se ha visto correspondido con la realidad. Actualmente, la situación social que viven los jóvenes provoca una permanencia media en el hogar familiar de hasta casi los 30 años.

\section{Otras reformas civiles}

En el artículo 50 de la Constitución se determina que los poderes públicos garantizarán, mediante pensiones ajustadas y adecuadas, el bienestar económico de los ancianos. A la vez, que el Estado les tiene que proporcionar un sistema de servicios sociales para atender a sus necesidades específicas de salud, vivienda, cultura y tiempo libre. En España, el 74,5\% de las pensiones son de vejez $^{47}$.

${ }^{47}$ Eurostat. Citado en Fuentes Estadísticas, n. ${ }^{\circ}$ 68, INE, 2001. 
La edad de jubilación, fijada en 65 años, ha sido modificada en algunos casos, como el de los profesores universitarios, que se elevó hasta los 70 años por considerarse que se basaba en una discriminación por edad. El problema que actualmente existe es que la subsistencia del régimen de pensiones sobre la base del reparto está amenazada tanto por la reducción de la fecundidad como por el aumento de la longevidad.

\section{REFORMAS PENALES}

\section{Anticoncepción}

En 1977 se suprimió el artículo 316 del Código Penal entonces vigente, por el que se sancionaba la venta y hasta la difusión del conocimiento de los anticonceptivos, lo cual no significa que no se utilizaran. Esta permisividad se vio apoyada por la creación de Centros de Planificación Familiar cuyo fin era proporcionar consejo y asistencia gratuita a las parejas que querían regular su fecundidad. Las medidas que han facilitado la planificación de la maternidad han traído como consecuencia las bajas tasas de natalidad existentes en la actualidad, que se remontan a los años ochenta, desde los cuales ya no se ha conseguido el nivel de reemplazo de las generaciones. Esta baja de la natalidad empieza a compensarse en parte por la población de inmigrantes, como lo prueba que, en el año 2000, el 8\% de los nacidos en España tenían madres extranjeras.

\section{Aborto}

En 1983 se despenalizó el aborto en tres supuestos: cuando la vida de la madre corre peligro, cuando el embarazo es resultado de una violación y en los casos de malformación del feto. A pesar de ello, sigue siendo tema de debate entre diferentes sectores ideológicos: unos pretenden añadir un cuarto supuesto económico-social, de estado de necesidad, y otros no lo admiten en ningún caso. La interrupción voluntaria del embarazo aumentó desde 16.766 casos en 1987 hasta 45.503 en 1993.

\section{La revolución reproductora}

El Plan de Centros de Orientación Familiar, elaborado en 1983 por el Ministerio de Sanidad, definió los criterios para su funcionamiento, el equipo y las prestaciones que se pueden ofrecer. En 1984 el INSALUD abrió 34 centros, que se sumaron a los 19 creados en 1978 por los Ministerios de Sanidad y Cultura y a los establecidos por las Comunidades Autónomas, las Diputacio- 
nes, los Ayuntamientos y los particulares, ascendiendo en 1990 a 641 el total de Centros de Orientación Familiar.

$\mathrm{Su}$ actividad no se limita legalmente a la anticoncepción, sino que también les corresponden funciones en cuanto a la esterilidad, una condición que en España afectaba, en torno a 1985, a entre 584.000 y 794.000 parejas casadas. Por aquel entonces, el $89,5 \%$ de los españoles de 16 a 65 años opinaban que "cuando una pareja no puede tener hijos y los desean, es normal que utilicen todos los medios médicos y científicos que puedan existir».

El primer Banco de semen se fundó en nuestro país en 1978 y se calcula que hacia 1988 habían nacido ya 2.000 niños por inseminación artificial. Además, las innovaciones en el campo de la reproducción se han multiplicado universalmente durante estos años y, en 1978, nació Louise Brown en el Reino Unido por fecundación in vitro (FIV) con transferencia de embriones (TE), mientras que entre nosotros el primero del medio centenar de los nacimientos habidos hasta 1991 tuvo lugar en 1984, en una clínica privada de Barcelona.

Al hilo de estos acontecimientos, el Congreso de los Diputados decidió nombrar el 2 de noviembre de 1984 una Comisión Especial de Estudio sobre Fertilización Extracorpórea, cuyos trabajos y conclusiones se recogieron definitivamente en un Informe que se aprobó en 1986 y que fue publicado al año siguiente. Sobre la base de sus recomendaciones y de otros estudios y acciones posteriores, las Cortes Generales aprobaron la Ley 35/1988, de 22 de noviembre, sobre técnicas de reproducción asistida, que intenta cubrir los más variados aspectos de los progresos científicos correspondientes. En su Exposición de Motivos trae a colación la sentencia de 11 de abril de 1985 del Tribunal Constitucional, que manifiesta que «la vida humana es un devenir», "un proceso que comienza con la gestación, en el curso del cual una realidad biológica va tomando corpórea y sensitivamente configuración humana que termina con la muerte».

La Ley regula las técnicas de reproducción humana asistida: la inseminación artificial (IA), la fecundación in vitro (FIV) con transferencia de embriones (TE) y la transferencia intratubárica de gametos (TIG). Da una primacía total a la paternidad social frente a la biológica, fija el criterio de considerar al embrión de 14 días como un ser humano, prohíbe tajantemente la fecundación de los óvulos humanos con cualquier fin distinto a la procreación humana y define las que considera infracciones graves y muy graves, que se sancionarán según dispone la vigente Ley de Sanidad.

Cuando el 24 de febrero de 1997 la prensa publicó la noticia de que los investigadores de la clínica Roslin, en Escocia, habían conseguido la clonación de la oveja Dolly, se abrió un nuevo capítulo en la historia de la reproducción animal y, seguramente, humana. Aunque no sabemos a ciencia cierta que se haya clonado ningún ser humano, científicos más o menos cuerdos de distintas partes de la tierra lo anuncian de vez en cuando y se ha universalizado la discusión sobre la licitud de utilizar células madre procedentes de embriones huma- 
nos congelados tanto para usos reproductivos como terapéuticos. La comunidad científica y las sociedades de los países avanzados debaten ambas posibilidades, aunque se hallan más divididas en cuanto a la segunda posibilidad y menos por lo que toca a la primera.

\section{LA FAMILIA EN EL SISTEMA DE PROTECCIÓN SOCIAL}

Durante la segunda mitad del siglo Xx, la protección social a la familia ha cambiado considerablemente, pasando de ser una de las dimensiones centrales en la época del franquismo a casi desaparecer. En la última década ha renacido el interés por la familia, debido a las funciones sociales que cumple en relación con determinados problemas que afectan a la sociedad española, como son la conciliación del trabajo y la familia, el paro o las drogas ${ }^{48}$. Durante decenios, la protección familiar se vinculó con la dictadura franquista y ello hizo que los poderes públicos la olvidaran a causa del recuerdo de la importancia política que le atribuyó la dictadura, que la convirtió en uno de su pilares, juntamente con el municipio y el sindicato.

Tradicionalmente, la protección brindada a la familia ha perseguido siempre como objetivo básico el de influir sobre la evolución demográfica y, especialmente, sobre la función social de la reproducción humana y el papel de la mujer dentro de ella. Los tipos de medidas en los que esta protección se canalizaba eran las prestaciones económicas de pago periódico por hijos a cargo, las desgravaciones fiscales y las reducciones en el precio de determinados servicios que suponían una forma indirecta de ayuda.

En el régimen franquista la familia fue una de las grandes beneficiarias del sistema de protección social, aunque en realidad se vivieron dos periodos: un primer momento de gran importancia, seguido de una decadencia de la ayuda prestada a la familia, según la evolución de ciertas prestaciones desde los años sesenta. En la primera etapa se produce un aumento considerable del gasto destinado a seguros sociales, que no es uniforme en todas las partidas. La familia, junto a la vejez, son en 1943 los principales beneficiarios. En el caso de la familia, como puede verse en el cuadro 35, con una dotación de 318,5 millones de pesetas, que no dejó de aumentar. En este periodo, otra de las partidas que adquiere importancia es el seguro de enfermedad, que ya a principios de los cincuenta supera los gastos destinados a los subsidios familiares $(1.522,5 \mathrm{y}$ 1.088,8 millones).

A partir de mediados de los años sesenta y hasta el final del régimen, en 1975, a pesar del aumento en términos absolutos de las ayudas a la familia, su importancia respecto al PIB ya no es la misma. Si en 1965 la cantidad de dinero aportado a la familia suponía el 2,6\% del PIB, diez años más tarde esa proporción se había reducido a la mitad (cuadro 36).

${ }^{48}$ J. Iglesias de Ussel y G. Meil, La política familiar en España, Ariel, Barcelona, 2001. 


\section{CUADRO 35}

Evolución del gasto en seguros sociales, 1943-1952 (en millones de pesetas)

\begin{tabular}{|c|c|c|c|c|c|}
\hline Tipos de seguros sociales & 1943 & 1945 & 1948 & 1950 & 1952 \\
\hline Seguro obligatorio vejez e invalidez ....... & 178,6 & 197,7 & 431,7 & $1.007,7$ & $1.439,1$ \\
\hline a) Rama general (1939) ..................... & 178,6 & 197,7 & 336 & 279,9 & 355,5 \\
\hline Rama agropecuaria (1943) ........ & - & & & 523,4 & 645,4 \\
\hline c) Mutualidades laborales (1943) .. & - & & 95,7 & 204,4 & 438,2 \\
\hline Seguro de enfermedades (1942) ............. & - & 198,7 & 544,4 & 962 & $1.522,5$ \\
\hline Subsidios familiares (1938) ..................... & 318,5 & $1.101,9$ & $1.113,9$ & 1.035 & $1.088,8$ \\
\hline TOTAL* & 497,1 & $1.498,3$ & 2.090 & $3.104,7$ & $4.050,4$ \\
\hline
\end{tabular}

* No están incluidos los seguros de accidentes de trabajo y enfermedad profesional por falta de datos. Los años entre paréntesis indican el año de creación del correspondiente seguro social.

FuENTE: Iglesias y Meil, La política familiar en España, Ariel, Barcelona, 2001, p. 45.

\section{CUADRO 36}

Evolución de las prestaciones familiares de la Seguridad Social, 1965-1976

\begin{tabular}{|c|c|c|c|c|c|}
\hline & 1965 & 1967 & 1970 & 1973 & 1975 \\
\hline $\begin{array}{l}\text { Prestaciones en millones pesetas constan- } \\
\text { tes de } 1976\end{array}$ & 39.698 & 34.537 & 38.962 & 57.904 & 59.348 \\
\hline Prestaciones en pesetas constantes de 1976 & & & & & \\
\hline $\begin{array}{l}\text { (números índices) }{ }^{*} \\
\text { Porcentaje sobre gastos corrientes }\end{array}$ & $\begin{array}{r}100 \\
48\end{array}$ & $\begin{array}{l}87 \\
35\end{array}$ & $\begin{array}{l}87 \\
24\end{array}$ & $\begin{array}{l}99 \\
17\end{array}$ & $\begin{array}{l}75 \\
11\end{array}$ \\
\hline Porcentaje sobre prestaciones económicas . & 64 & 52 & 36 & 26 & 17 \\
\hline 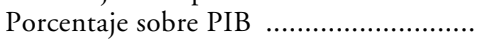 & 2,6 & 2 & 1,6 & 1,5 & 1 \\
\hline
\end{tabular}

* Las prestaciones familiares que se incluyen son tanto las nuevas prestaciones (asignaciones por hijo, cónyuge a cargo, por matrimonio y por nacimiento, así como los premios a la natalidad) como las prestaciones del antiguo sistema para quienes, en reconocimiento de sus derechos adquiridos, no hubiesen optado por el nuevo sistema.

FUENTE: Iglesias y Meil, La política familiar en España, Ariel, Barcelona, 2001, p. 61.

Este descenso respecto al PIB coloca a España en una situación intermedia en relación con los demás países europeos. Todos han bajado el porcentaje, pero los que más aportan siguen siendo los mismos desde la década de los cuarenta. En 1974, Bélgica y Francia son los que más contribuyen (2,6 y 2,7 del PIB, respectivamente), frente a los países que lo hacen menos, que son Alemania, Reino Unido y Noruega (0,4, 0,5 y 1, respectivamente). España, como se ha apuntado anteriormente, está en 1,2, una posición intermedia que comparte con otros países como Dinamarca o Irlanda (cuadro 37). 


\section{CUADRO 37}

Porcentaje de las prestaciones familiares de la Seguridad Social respeto al PIB en distintos paises europeos, 1949-1974

\begin{tabular}{|c|c|c|c|c|c|c|c|c|c|c|c|c|c|}
\hline & & $A U$ & $B E$ & $D K$ & $F R$ & $G E$ & $I R$ & $I T$ & $N E$ & $N O$ & $S W$ & $U K$ & ESP \\
\hline 949 & & - & 1,2 & 0 & n.d. & n.d. & n.d. & 1,7 & 1,4 & 0,5 & 1,1 & 0,6 & n.d. \\
\hline 950 & & 1,1 & 1,7 & 0 & & & & & & & 1,1 & 0,6 & n.d. \\
\hline 951 & & 1,9 & 1,7 & 0,5 & & & & & & & 1,2 & 0,6 & \\
\hline 952 & & 1,9 & 1,7 & 0,5 & & & & & & & & 6 & \\
\hline 3 & & 1, & 1, & 0 & & & & & & & & & \\
\hline 4 & & 1,7 & 2,0 & 0,6 & 3,4 & & & & 4 & & & & \\
\hline & & 1,4 & 1 , & 0,6 & & & & & & & & & \\
\hline & & & 1 , & 0 & & & & & & & & & \\
\hline & & 1,2 & 2,0 & 0,6 & 3 , & & & & & & & & n.d. \\
\hline & & 1,6 & 2,1 & 0,6 & 3 , & & 1,2 & & & & & & 2,7 \\
\hline & & 1,6 & 2,0 & 0 , & 3 , & & 1,3 & & & & 1,3 & & \\
\hline 960 & & 1,4 & 2,1 & 0,4 & 3,0 & 0,3 & 1,2 & 2,1 & & & 1,4 & n.d. & 2,8 \\
\hline 961 & & 1,8 & 2,3 & 0,4 & 3,0 & 0,3 & 1,1 & 2,0 & 1,4 & & 1,0 & 0,5 & n.d. \\
\hline 962 & & 2,0 & 2,3 & 1,2 & 3,0 & 0 , & 1,0 & & & & 1,1 & 5 & 2,5 \\
\hline 963 & & 2,1 & 2,4 & 1,2 & 3,0 & 0, & 1,0 & & & & & 5 & 2,6 \\
\hline 964 & & 2,1 & 2,4 & 1,2 & 3,0 & & 1,0 & & & & & 5 & 2,8 \\
\hline 06 & & 2,0 & 2, & 1,0 & 2,9 & 0,4 & 1,1 & & 2,0 & & 1,2 & 5 & 2,6 \\
\hline 96 & & 2,0 & 2 & 1,2 & 2,8 & 0, & 1,1 & & 2,1 & & 1 , & 4 & 1,5 \\
\hline 7 & & 2,1 & 2 , & 1,1 & & & & & & & & 4 & 2,0 \\
\hline & & 2 & 2 & & & & & & & & & & ,8 \\
\hline & & 2,1 & 2 , & 1, & & & & & & & & & 1,8 \\
\hline 97 & & 1,9 & 2 , & 1,1 & & & 1 , & 1, & & & 0 , & & 1,6 \\
\hline & & 1,9 & 2, & 1,4 & n.d. & & 1 , & 1 , & & & 1 , & & 1,9 \\
\hline & & 1,8 & 2,6 & 1,4 & 2,4 & 0,4 & 0,9 & 1, & 2,0 & & 1,1 & 6 & 1,7 \\
\hline & & 1,7 & 2,5 & 1,3 & 2,5 & 0 , & 0,8 & & & & 1,1 & 6 & 1,5 \\
\hline 974 & & 1,6 & 2,6 & 1,2 & 2,7 & 0,4 & 1,3 & 1,7 & 1,9 & 1,0 & 1,2 & 0,5 & 1,2 \\
\hline
\end{tabular}

n.d.: no disponible.

FueNTE: Iglesias y Meil, La politica familiar en España, Ariel, Barcelona, 2001.

A mitad de los años ochenta las partidas a las que se dedicaban más ayudas eran la vivienda y la invalidez, según muestra el cuadro 38. Paradójicamente, la partida "familia e hijos», que incluye prestaciones por maternidad y por familia, era la que menos recibía. A principios de los noventa se observa un aumento poco importante; la vivienda, uno de los grandes problemas de la sociedad actual, bastante relacionado con la familia, es la partida que más sube: un $5.760 \%$. Otras que han aumentado han sido la supervivencia, la vejez y la exclusión social.

Las ayudas percibidas en la partida familiar son de diferente naturaleza, bien prestaciones directas o bien beneficios fiscales. Han disminuido las prestaciones directas y han aumentado las fiscales. Respecto a las primeras, la mater- 


\section{CUADRO 38}

Evolución del gasto en pesetas corrientes de las principales partidas del gasto en protección social (en números índices)

\begin{tabular}{|c|c|c|c|}
\hline & 1980 & 1985 & 1990 \\
\hline Prestaciones de protección social ...................... & 100 & 207 & 382 \\
\hline Función «enfermedad, atención sanitaria» ....... & 100 & 174 & 352 \\
\hline 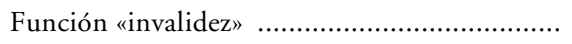 & 100 & 240 & 444 \\
\hline Función $«$ vejez» & 100 & 224 & 403 \\
\hline Función «supervivencia» & 100 & 193 & 323 \\
\hline 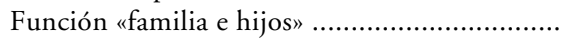 & 100 & 115 & 164 \\
\hline 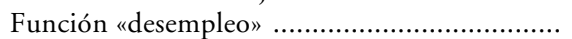 & 100 & 246 & 433 \\
\hline 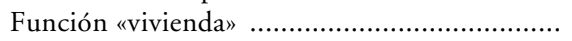 & 100 & 516 & 5.760 \\
\hline 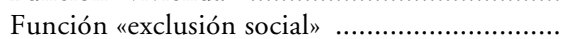 & 100 & 147 & 258 \\
\hline
\end{tabular}

Fuente: Iglesias y Meil, La política familiar en España, Ariel, Barcelona, 2001, p. 97.

nidad ha sido la beneficiaria de este grupo, que pasó de 55.662 pesetas en 1980 a 57.781 pesetas en 1990. Por el contrario, las prestaciones y asignaciones por hijo y las subvenciones a guarderías infantiles, alimentación infantil y otros servicios disminuyeron considerablemente (116.997 a 48.108 pesetas). Las prestaciones fiscales, en cambio, sí han aumentado, tanto por matrimonio como por hijos.

El cuadro 40, que muestra las prestaciones únicas y bajo condición de recursos, nos ofrece información adicional a la de las prestaciones periódicas (también recogidas en el mismo cuadro), habiendo pasado el porcentaje de ayuda por hijos respecto al PIB de 0,7 a 0,3, es decir, reduciéndose más de un $50 \%$.

En cuanto a la natalidad, estas ayudas únicas no tienen actualmente ninguna importancia y el cuadro nos muestra cómo la han ido perdiendo. Algunas prestaciones que sí han aumentado han sido las de guardería, alojamiento y ayuda a domicilio, que se hallan muy relacionadas hoy día con la atención a las personas mayores.

La evolución en porcentajes de estas ayudas puede aclarar lo que hemos venido afirmando hasta ahora. Distingamos entre con condición o sin condición de recursos. Respecto a las ayudas con condición de recursos, éstas han pasado de ser el $10 \%$ a ser el $36 \%$. Han disminuido las prestaciones en dinero y las asignaciones por hijo a cargo (ambas han pasado del 24 al 17\%), y han aumentado las prestaciones en especie y el alojamiento (de 10 a $18 \%$ y de 2 a $9 \%$, respectivamente).

La situación económica de las familias una vez percibidas las ayudas y las ventajas fiscales es la siguiente: el número de familias que viven con la mitad 


\section{CUADRO 39}

Gastos en protección social directa y fiscal a la familia en España, 1980-1990* (en millones de pesetas de 1983 y números índices)

\begin{tabular}{|c|c|c|c|c|c|}
\hline & 1980 & 1983 & 1985 & 1988 & 1990 \\
\hline 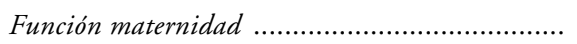 & 55.662 & 54.324 & 51.697 & 54.943 & 57.781 \\
\hline 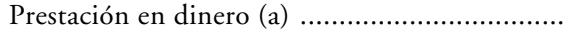 & 13.055 & 13.338 & 13.530 & 13.924 & 14.281 \\
\hline Prestación en especie (b) ......... & 42.607 & 40.986 & 38.167 & 41.019 & 43.500 \\
\hline Función familia ............. & 116.997 & 83.868 & 67.108 & 51.809 & 48.108 \\
\hline Prestación en dinero $(\mathrm{c})$. & 99.433 & 67.615 & 50.816 & 33.658 & 29.734 \\
\hline Prestación en especie (d) & 17.564 & 16.252 & 16.292 & 18.150 & 18.375 \\
\hline Total prestaciones a & 172.659 & 138.192 & 118.805 & 106.752 & 105.889 \\
\hline Prestaciones directas (número índice) …............. & 100 & 80 & 69 & 62 & 61 \\
\hline & & & & & 989 \\
\hline 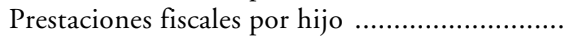 & 89.377 & 106.241 & 105.460 & 106.349 & 106.181 \\
\hline 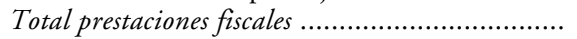 & 161.453 & 188.157 & 194.074 & 215.335 & 213.170 \\
\hline Prestaciones fiscales (número índice) …............... & 100 & 117 & 120 & 133 & 132 \\
\hline Total prestaciones a familia (sin maternidad) ..... & 278.450 & 272.025 & 261.182 & 267.144 & 261.278 \\
\hline Prestaciones familiares (número índice) …....... & 100 & 114 & 123 & 96 & 94 \\
\hline Porcentaje prestaciones fiscales sobre total ....... & 58 & 69,2 & 74,3 & 80,6 & 81,6 \\
\hline
\end{tabular}

* Estos datos están elaborados con arreglo a la metodología SEEPROS de Eurostat; incluyen, por tanto, no sólo las prestaciones directas de la Seguridad Social, sino también las prestaciones familiares de la mutualidad de funcionarios, así como determinadas prestaciones en especie.

(a) Incluye el salario de sustitución durante el permiso por maternidad, así como la asignación por nacimiento (suprimida en 1985 salvo para funcionarios, a quienes se suprime en 1990).

(b) Corresponde a las estimaciones de gasto sanitario destinado a maternidad.

(c) Corresponde a asignaciones por hijo y, hasta 1987, salvo funcionarios, otras personas a cargo, asignaciones por matrimonio (suprimidas en 1985 salvo para funcionarios, a quienes se suprimen en 1990).

(d) Corresponde a subvenciones a guarderías infantiles, alimentación infantil en centros de enseñanza y otros servicios.

FuENTE: Iglesias y Meil, La politica familiar en España, Ariel, Barcelona, 2001, p. 100.

o menos del salario medio es 1.289.400, y el número de familias que viven con dos salarios medios alcanza la cifra de 5.157.7600 (cuadro 41). Respecto a las diferencias entre las formas familiares, podemos deducir que de las familias que viven con menos del salario medio, las que se encuentran en peor situación son las de mujeres separadas o divorciadas. En el otro extremo, los que más se benefician son los matrimonios con cuatro hijos y las parejas, casadas o no, con dos hijos. Respecto a las familias que están en una situación intermedia, los menos beneficiados son los solteros sin hijos y las parejas cohabitantes sin hijos. 


\section{CUADRO 40}

Evolución de los gastos destinados a la protección función "familia, hijos» (en términos porcentuales)

\begin{tabular}{|c|c|c|c|c|c|c|}
\hline & 1980 & 1985 & 1990 & 1994 & 1995 & 1996 \\
\hline 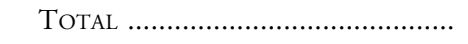 & 100 & 100 & 100 & 100 & 100 & 100 \\
\hline Sin condición de recursos ..................... & 90 & 86 & 85 & 61 & 65 & 64 \\
\hline 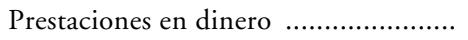 & 85 & 79 & 74 & 54 & 57 & 57 \\
\hline Mantenimiento renta maternidad ...... & 7 & 13 & 21 & 21 & 23 & 28 \\
\hline Asignación por hijo a cargo ................ & 66 & 51 & 29 & 16 & 17 & 18 \\
\hline Otras prestaciones periódicas ............. & 1 & 0 & 0 & 0 & 0 & 1 \\
\hline 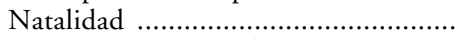 & 1 & 1 & 0 & 0 & 0 & 0 \\
\hline Otras prestaciones. Únicas .................. & 11 & 14 & 24 & 17 & 0 & 11 \\
\hline Prestaciones en especie ......................... & 5 & 8 & 11 & 7 & 7 & 7 \\
\hline Bajo condición de recursos ................... & 10 & 14 & 15 & 39 & 35 & 36 \\
\hline Prestaciones en dinero .......................... & - & - & - & 24 & 21 & 17 \\
\hline Asignación por hijo a cargo ................. & - & - & - & 24 & 21 & 17 \\
\hline Únicas. Otras prestaciones ................. & - & - & - & - & - & - \\
\hline Prestaciones en especie .......................... & 10 & 14 & 15 & 14 & 14 & 18 \\
\hline 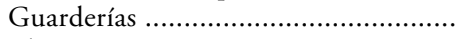 & 1 & 1 & 2 & 1 & 2 & 1 \\
\hline 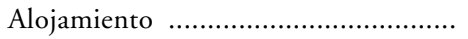 & 2 & 3 & 3 & 3 & 3 & 9 \\
\hline Ayuda a domicilio ................................ & 0 & 0 & 0 & 0 & 0 & 0 \\
\hline 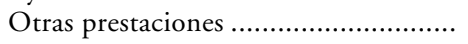 & 7 & 10 & 10 & 10 & 10 & 8 \\
\hline
\end{tabular}

NoTA: Con arreglo a la metodología SEEPROS, versión 1995, que combina las asignaciones familiares y maternidad, pero sin incluir los gastos sanitarios.

Fuente: Iglesias y Meil, La política familiar en España, Ariel, Barcelona, 2001, p. 120.

Gerardo Meil, al analizar el sistema de protección social y su vinculación con la familia, parte de una idea básica, y es la de que, como consecuencia de los cambios producidos tanto en la consideración como en el funcionamiento de la familia, su papel en el sistema de protección familiar está variando. Desde el punto de vista de los modelos de organización de la vida familiar se ha pasado del ideal de familia tradicional, entendida como un proyecto de convivencia con carácter público para toda la vida y con segregación radical de los roles y de los ámbitos de decisión en función del sexo, a un modelo ideal menos claramente fijado que se distingue, sobre todo, por la pérdida de legitimidad del control social sobre este aspecto de la vida de los individuos y la creciente libertad de conformación individual de los proyectos de convivencia ${ }^{49}$. La tradición era la base lógica de la organización tradicional de la familia, en la que el hombre era el sustentador de la familia y la mujer se quedaba en casa. La

49 Cita de Lüscher (1998) en Meil, «Los desafios del sistema de protección social derivados de la postmodernización de la familia", Arbor, CLXXIV, 685 (enero 2003), pp. 163-193. 


\section{CUADRO 41}

Renta disponible después de impuestos y transferencias familiares en 1997 según distintas situaciones familiares y de renta

\begin{tabular}{|c|c|c|c|c|c|}
\hline Ingresos & $\begin{array}{c}0,5 \\
\text { salario } \\
\text { medio }\end{array}$ & $\begin{array}{c}\text { Salario } \\
\text { medio }\end{array}$ & $\begin{array}{c}1,5 \\
\text { salario } \\
\text { medio }\end{array}$ & $\begin{array}{c}\text { Salario } \\
\text { medio } \\
\text { y } 0,66 \\
\text { salario } \\
\text { medio }\end{array}$ & $\begin{array}{c}\text { Dos } \\
\text { salarios } \\
\text { medios }\end{array}$ \\
\hline Salario bruto . & 1.289 .400 & 2.578 .800 & 3.868 .200 & 4.280 .800 & 5.157 .600 \\
\hline \multicolumn{6}{|l|}{ Porcentaje renta netalbruta } \\
\hline 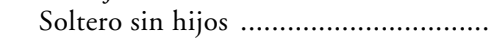 & 92,9 & 83,7 & 80 & 79 & 77,2 \\
\hline 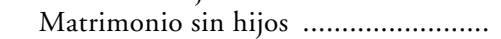 & 96,8 & 88,4 & 83,9 & 85,4 & 83,7 \\
\hline 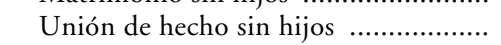 & 92,9 & 83,7 & 80 & 85,4 & 83,7 \\
\hline Matrimonio con 2 hijos ....................... & 100,6 & 90,2 & 85 & 86,5 & 84,5 \\
\hline Unión de hecho con 2 hijos ............... & 95,2 & 85,4 & 81,2 & 86,5 & 84,5 \\
\hline Separada/divorciada con 2 hijos ......... & 100,6 & 90,2 & 85 & 79,5 & 81,4 \\
\hline 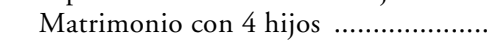 & & 92,4 & 86,5 & 87,8 & 85,7 \\
\hline \multicolumn{6}{|l|}{ Aumento respecto a un soltero (\%) } \\
\hline Matrimonios sin hijos ............................ & 3,9 & 4,8 & 3,8 & 6,4 & 6,5 \\
\hline Unión de hecho sin hijos ..................... & 0 & 0 & 0 & 6,4 & 6,5 \\
\hline 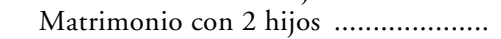 & 7,7 & 6,5 & 5 & 7,5 & 7,3 \\
\hline Unión de hecho con 2 hijos ............... & 2,3 & 1,7 & 1,1 & 7,5 & 7,3 \\
\hline Separada/divorciada con 2 hijos ........ & 7,7 & 6,5 & 5 & 0,5 & 4,2 \\
\hline Matrimonios con 4 hijos ....................... & & 8,8 & 6,5 & 8,8 & 8,5 \\
\hline
\end{tabular}

Fuente: Iglesias y Meil, La politica familiar en España, Ariel, Barcelona, 2001, p. 126.

importancia de la libertad de opción para que el individuo construya su propio ciclo vital empieza a hacer mella en la familia tal como la hemos conocido hasta ahora.

Ahora bien, los cambios producidos en la familia no se limitan al proceso de individualización, puesto que también otros aspectos de la familia se han visto influidos por la modernización. En este sentido, Meil alude a otros tipos de familia como las monoparentales, a los hogares unipersonales, a los divorcios, etc., que tienen gran importancia a la hora de analizar el sistema de protección social español, en el que la familia era antes un pilar básico.

En conjunto, el cambio familiar se ha traducido en una pluralización de los modos de entrada, permanencia y salida de la vida familiar y en una mayor libertad individual para definir el proyecto conyugal y familiar, lo que significa que el modelo tradicional está cada vez menos presente entre las nuevas generaciones y esto tiene consecuencias en el sistema de protección social ${ }^{50}$.

50 Ibidem. 


\section{OBSERVACIONES FINALES}

Al llegar a este punto, establecer hacia dónde evolucionará la familia española en los próximos años es un ejercicio sumamente arriesgado, si bien lo es menos que describir hacia dónde la impulsan algunas de las tendencias recientes que se pueden identificar, tanto en su interior como en la dinámica de la sociedad global, así como la influencia que sobre ella ejercen determinados factores importantes.

Ante todo, hay que tener presente que la estructura familiar que prevalece hoy en España es la que también impera aún en las sociedades occidentales, a saber, la familia nuclear o conyugal, y que las fórmulas pretendidamente alternativas a ella han sido en no pocos casos experiencias temporales, puestas en práctica sobre todo por una minoría bastante reducida, generalmente de jóvenes. Ahora bien, la familia en cuanto modelo universal está adaptándose a la diversidad creciente de las situaciones personales propias de nuestras complejas sociedades y está adquiriendo formas nuevas, que afectan tanto a las relaciones de pareja como a los hijos.

La primera adaptación perceptible tiene que ver con la liberalización de las relaciones de pareja y con la desvalorización o relativización de los formulismos o rituales. Así ha pasado, según hemos visto, con el noviazgo, pero algo análogo le sucede al matrimonio mismo a causa de la extensión de las uniones consensuales, que prescinden de todo vínculo legal. La cohabitación como figura real de la familia sale de la clandestinidad al llegar la democracia. Aun así, las encuestas más solventes demuestran que se trata de un fenómeno minoritario, personalmente pasajero y que a menudo termina en matrimonio $^{51}$.

Otra tendencia importante, que se afirmó al hacerlo la secularización de la sociedad, es el mayor número de los matrimonios estrictamente civiles y, por tanto, la deserción del católico, que de abarcar el 95,5\% del total de los celebrados en 1980 se redujo en 1986 al 84,2\% y en 1992 al 79,2\%52. En la actualidad los matrimonios civiles suponen el $24 \%$ del total de los matrimonios celebrados ${ }^{53}$.

La siguiente tendencia tiene que ver con la reducción del número de hijos. Todo hace pensar que la baja fecundidad de los matrimonios se va a mantener en el futuro, de modo que las familias contarán con uno o dos hijos a lo sumo y que aumentará o permanecerá igual el porcentaje de las que no tendrán ninguno. Además, aunque el acortamiento del periodo fecundo será la norma, se enriquecerá la gama de opciones, porque habrá parejas que seguirán teniendo

51 Véase VV.AA., La cohabitación en España. Un estudio en Madrid y Barcelona, Estudios y Encuestas, 8, Centro de Investigaciones Sociológicas, Madrid, 1988, pp. 133 y ss.

52 Cfr. Margarita Delgado Pérez y J. Fernández Cordón, Análisis de las cifras de matrimonio en España desde 1975, Instituto de Demografía, CSIC, Madrid, 1989, e INE, Panorámica Social, Madrid, 1995, tabla 2.8 .

${ }_{53}$ Movimiento Natural de la Población, 1979-1995; Anuario Estadístico, 2000, INE. 
su primer hijo en los dos años iniciales del matrimonio, mientras que otras decidirán retrasar su paternidad. Es decir, asistiremos a una generalización mayor de la planificación familiar, que repercutirá sobre la diversidad de las situaciones familiares y que dependerá también del avance de las técnicas médicas que la favorezcan.

El fracaso matrimonial, que en la sociedad española ya es aceptado socialmente y resuelto por el divorcio, sigue todavía sometido a algunas limitaciones provocadas por las objeciones morales que se le formulan, pero se ve afectado sobre todo por sus consecuencias económicas para las partes y por la atención que hay que prestar a los hijos. Seguramente, el número de divorcios se incrementará por la utilización que de él harán las parejas de clases sociales menos acomodadas y por la elevación del nivel de vida.

El resultado de todo esto se plasmará en el aumento del número de las familias monoparentales, que se nutren de las mujeres y de los hombres que no se han casado, así como de los que han visto rotos sus matrimonios por defunciones del cónyuge u otro motivo. En 1991 había 837.000 mujeres y 136.000 hombres en familias de este tipo, suponiendo estas cifras un crecimiento del 14 por 1.000 para las mujeres y un descenso del 43 por 1.000 para los hombres, en ambos casos desde $1981^{54}$.

La situación de las familias monoparentales en el año 2002 se presenta en el cuadro 42. De las 285.000 familias monoparentales que existen en España, el $89,45 \%$ están encabezadas por mujeres: el $71,47 \%$ por mujeres menores de 45 años y el resto por mujeres mayores de 45 años. Esto sugiere que la monoparentalidad se relaciona actualmente más con las mujeres separadas, divorciadas o solteras que con las nuevas formas de vida y está dejando de ser un fenómeno propio de las mujeres viudas, que hasta hace poco habían tenido el protagonismo en este tipo de convivencia.

Es probable, asimismo, que en el futuro ascienda todavía más el número de las personas que viven solas, debido a tres situaciones diversas: la de los hombres y mujeres que deciden no casarse (con independencia del tipo de relaciones sexuales que puedan mantener); la de los hombres y mujeres que disuelven o ven truncados sus matrimonios sin haber tenido hijos y acuerdan no volver a casarse; y, por último, la de aquellas personas de la tercera edad - principalmente mujeres - que se han quedado sin familia. El conjunto de estos tres grupos, que sumaban 1.085.078 personas, abarcaba en el Censo de Población de 1981 el 10,25\% de todos los hogares, y ascendía en algunas zonas rurales a más del $15 \%$.

Los problemas de la tercera edad, no sólo por sus repercusiones sobre la sociedad, sino también por sus efectos sobre las relaciones internas de la familia, condicionarán en alguna medida las futuras relaciones entre los padres y

${ }^{4}$ Julio Iglesias de Ussel, «La situación de la familia en España y los nuevos modelos familiares», en Las familias monoparentales, Ministerio de Asuntos Sociales, Madrid, 1988, y Salustiano del Campo, «Hogares y Familias en España», Cuenta y Razón, 90, febrero-marzo 1995, pp. 44-47. 


\section{CUADRO 42}

Familias monoparentales según sexo y grupos de edad de la persona de referencia (datos en miles)

\begin{tabular}{|c|c|c|c|c|c|c|}
\hline & \multicolumn{2}{|c|}{ Total } & \multicolumn{2}{|c|}{ Mujeres } & \multicolumn{2}{|c|}{ Hombres } \\
\hline & Absoluto & $\%$ mujeres & Absoluto & $\%$ & Absoluto & $\%$ \\
\hline TOTAL ............................. & 285,3 & 89,45 & 255,2 & 100 & 30,1 & 100 \\
\hline Menores de 45 años ............ & 197,1 & 92,54 & 182,4 & 71,47 & 14,6 & 48,50 \\
\hline De 45 a 59 años ................... & 85,7 & 83,78 & 71,8 & 28,13 & 13,9 & 46,18 \\
\hline De 60 y más años ................. & 2,5 & 36,40 & 0,9 & 0,36 & 1,6 & 5,32 \\
\hline
\end{tabular}

Fuente: Encuesta de Población Activa, 1. ${ }^{\text {er }}$ trimestre 2002.

los hijos. Las tendencias a tener menos hijos y a dudar sobre si constituir una familia o no pueden estar relacionadas con el hecho de que la vejez ha pasado como preocupación desde el ámbito familiar al social. Al restarle competencias en este aspecto, la familia se vacía aún más de funciones y pierde sentido para quienes no valoran en exceso las que aún le quedan.

Otros cambios posibles de la familia española dependerán de las venideras condiciones económicas, tecnológicas y sociales del país, si bien cabe apostar que favorecerán su democratización interna y, en especial, reforzarán el papel de la mujer, que se igualará más con el del hombre dentro del hogar, mediante la negociación del contenido y despliegue de sus roles respectivos, viéndose menos discriminada en el mundo del trabajo, siquiera sea porque su nivel educativo cada día se acercará más al de los varones o lo superará. A causa de todo ello y de otros factores a los que antes me he referido, es posible que suba la proporción de los hogares cuyo cabeza de familia sea una mujer. 


\begin{abstract}
The transition from the extended family to the nuclear family occurred in Spain before the fifties, when the model for married life, together with limited and decreasing fertility, imposed themselves on us. The sixties were decisive for Spanish society, and within it the many changes occurring in the family had great repercussions, such as the reduction of the average size of the family, because of the reduction in the birth rate and the exit of other relatives from the home.

As from the eighties, evolution became accentuated and the nuclear family stopped being almost universal, moving closer to the models prevalent in Europe, while preserving some characteristics shared with other Mediterranean countries. Besides this, the new transformation of the family detached itself from the structural parameters that typified the change from traditional to advanced industrial society, turning into an eminently cultural society, as can be seen in characteristics such as the increase in the number of children born out of wedlock and of consensual couples, single-parent families and family tensions arising out of the change in the status of women in society.

Family planning has become common practice and, although abortion has been legalized in certain cases, general opinion is against making it freely available. Family relationships are progressively moving towards equality between spouses and is evident in decision-making and in helping in the home. Strain in Spanish marriages is relatively low and marital break-up has not reached the same levels as it has in Europe. As for family policy, the article mentions legal reforms, both civil and criminal, and the evolution of social protection of the family from 1943 up to the present.
\end{abstract}

